\title{
THERMAL DEGRADATION CHEMISTRY OF POLY(ETHYLENE NAPHTHALATE) - A STUDY BY THERMAL VOLATILISATION ANALYSIS
}

\author{
L. Turnbull ${ }^{\mathrm{a}}$, J.J Liggat $^{\mathrm{a}^{*}}$, W.A. MacDonald ${ }^{\mathrm{b}}$ \\ ${ }^{a}$ Department of Pure and Applied Chemistry, University of Strathclyde, 295 Cathedral Street, Glasgow, G1 1XL \\ ${ }^{\mathrm{b}}$ DuPont Teijin Films, PO Box 2002, Wilton, Middlesbrough, TS90 8JF, UK \\ * Corresponding author: Dr J.J. Liggat, Phone: +44 0141548 4351; Fax: +44 0141548 4822; \\ E-mail: j.j.liggat@strath.ac.uk
}

\begin{abstract}
:
Although the fundamental degradation chemistry of poly(ethylene naphthalate), PEN, is thought to be similar to that of poly(ethylene terephthalate), PET, there is very little evidence in the literature to support this. This paper presents data on the thermal degradation of PEN, in comparison to PET, with particular reference to evolved gas analysis undertaken by thermal volatilisation analysis (TVA). Our thermal degradation studies highlight strong similarities in the degradation behaviour of PET and PEN, despite some evidence of increased thermal stability of PEN in comparison to PET. Identical primary and secondary thermal degradation mechanisms are proposed for PET and PEN, with radical degradation processes thought to dominate at high temperature.
\end{abstract}

\section{KEYWORDS:}

Poly(ethylene terephthalate); Poly(ethylene naphthalate); Degradation; Evolved gas analysis; Mechanism 


\section{INTRODUCTION}

\subsection{Introduction to Polyesters}

Synthetic polymers continue to play a significant role in society today due to their extensive applications. Modern lifestyles would be impossible without synthetic polymers used to produce valuable products such as protective packaging, insulation materials in buildings, medical devices and key components for diverse applications such as renewable energy production. Aromatic polyesters, in particular, are currently one of the most important classes of synthetic thermoplastic polymers in use today, with applications as diverse as clothing, furnishings, protective packaging, medical devices, automotive components and building products. Increasingly, such polyesters are finding applications in electronic and solar energy markets as alternatives to more expensive polymers.

Following synthesis of the first linear aromatic polyester, poly(ethylene terephthalate) (PET) by Whinfield and Dickson in 1941, ${ }^{[1,2]}$ PET has become a leading commercial polymer, accounting for $6.5 \%$ of the total world plastic demand in 2011. ${ }^{[3]}$ Its major commercial uses remain as a textile fibre, material for blow moulded bottles and biaxially oriented film used for packaging, advanced photo systems, electrical and electronic applications. Although the demand for PET remains very strong, improved thermal and mechanical properties are required for some applications that PET cannot provide. One polymer that can provide such properties is poly(ethylene naphthalate) (PEN). PEN incorporates naphthalene rings into the polymer backbone rather than the phenyl rings in PET. These naphthalene units stiffen the polymer backbone resulting in a higher glass transition temperature and improved thermal, mechanical, electrical and barrier properties, in comparison to PET. ${ }^{[4,5]}$ Although PEN was first produced in 1948, it is now only beginning to make a major appearance into the market place due to the limited of the starting monomer, dimethyl-2,6-naphthalenedicarboxylate (NDC). Large-scale production of NDC was only introduced in the early 1990's leading to a significant increase in the raw material feed stocks for the production of PEN, reducing the overall cost of PEN resin. ${ }^{[6,7]}$ This has led to a substantial increase in the production and applications of PEN, with PEN now competing with PET in certain performance-driven markets based on its superior strength, heat stability and barrier properties.

\subsection{Thermal Degradation of Polyesters}

During manufacture and processing, PEN is exposed to higher temperatures than PET, due to its high melt temperature and high melt viscosity. Therefore, despite the apparent increase in thermal stability of PEN, in comparison to PET, degradation reactions at high processing temperatures will occur. These degradation reactions will lead to a drop in molar mass, evolution of volatile degradation products and loss of crucial polymer properties. 
Although the fundamental degradation chemistry of PEN is believed to be similar to that of PET, there is very little evidence in the literature to support this. A small number of studies exist on the photodegradation of PEN and PET/PEN polymer blends but no reports exist on the purely thermal degradation of PEN, although we have published on ageing of PEN in relatively low temperature conditions $\left(<200{ }^{\circ} \mathrm{C}\right) .{ }^{[8]}$ Botelho et al. ${ }^{[9]}$ published the first thermo-oxidative degradation study of PEN in the year 2000. These authors focused on the thermo-oxidative degradation of PEN using the model compound ethylene dinaphthoate (EDN) to deduce thermo-oxidative degradation mechanisms. FTIR studies indicated the presence of anhydride groups in PEN, thought to originate from the processing of films. Carboxylic acid groups were also detected alongside hydroperoxide species indicating that thermal degradation of PEN occurs simultaneously with thermo-oxidative degradation. Furthermore, GC-MS analysis indicated the formation of naphthoic acid alongside that of ethyl naphthoate. The formation of such compounds was explained by the homolytic cleavage of the C-O ester linkage followed by abstraction of a hydrogen radical. Trace quantities of additional degradation products were observed from thermo-oxidative degradation studies of the model compound ethylene dinaphthoate. These degradation products led Botelho et al. to believe that the thermo-oxidative degradation mechanism of PEN involves the oxidation of the methylene group in the position alpha to the ester group as illustrated in Scheme 1. This mechanism is identical to that proposed for PET by Buxhaum. ${ }^{[10]}$<smiles>Cc1ccc2cc(C(=O)OCCOC(=O)c3ccc4cc(C)ccc4c3)ccc2c1</smiles><smiles>CCOC(=O)c1ccc2cc(C)ccc2c1</smiles><smiles>Cc1ccc2cc(C(=O)O)ccc2c1</smiles><smiles>CCOC(=O)c1ccc2cc(C(C)C)ccc2c1</smiles>

\section{Scheme 1: Oxidative chain scission of ester linkages in PEN ${ }^{[10]}$}

Other than the thermo-oxidative mechanistic details, outlined in Scheme 1, details of the degradation of PEN remain limited, particularly purely thermal degradation. This paper therefore presents data on the thermal degradation of PEN with particular reference to evolved gas analysis undertaken by 
thermal volatilisation analysis (TVA). In addition, comparative data for PET is presented. In contrast to PEN, PET has been studied in some detail and its fundamental degradation mechanism established. ${ }^{[11-13]}$ Thermal cleavage of the ester bonds in the PET backbone results in the formation of vinyl ester and carboxylic acid end groups, as illustrated in Scheme 2. A cascade of secondary reactions leads to a wide range of small molecule products, outlined for PET in Scheme 3.

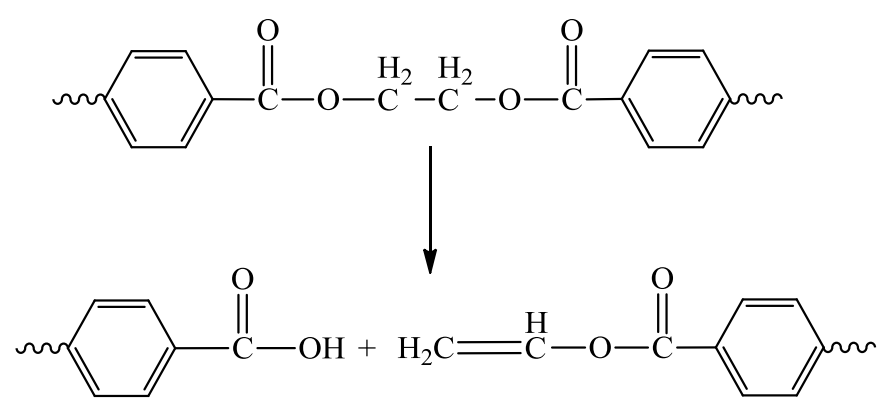

Scheme 2: Fundamental scission process in PET

\section{EXPERIMENTAL}

\subsection{Materials}

Commercial samples of PET and PEN were kindly supplied by DuPont Teijin Films. Both PET and PEN were supplied as transparent chips with a weight average molar mass $\left(M_{w}\right)$ of $24900 \pm 141 \mathrm{~g} \mathrm{~mol}^{-1}$ and $20200 \pm 71 \mathrm{~g} \mathrm{~mol}^{-1}$, respectively. Prior to use, the polyester chips were stored for several hours in a vacuum desiccator at room temperature, to remove any surface water.

\subsection{Differential Scanning Calorimetry (DSC)}

All samples were analysed using a TA Q1000 DSC equipped with a RC90 refrigerated cooling system. The instrument was calibrated with a standard of indium and all samples were prepared in aluminium hermetic DSC pans. Dynamic DSC degradation experiments were performed by heating $6 \mathrm{mg}$ samples from $30-550{ }^{\circ} \mathrm{C}$, at a heating rate of $10{ }^{\circ} \mathrm{C} \mathrm{min}^{-1}$. Analyses were performed under nitrogen with gas flow rates of $60 \mathrm{~mL} \mathrm{~min}^{-1}$. All data was processed using TA software and all temperature values quoted from the DSC curves were rounded to the nearest integral value, with an error of $\pm 1{ }^{\circ} \mathrm{C}$. 

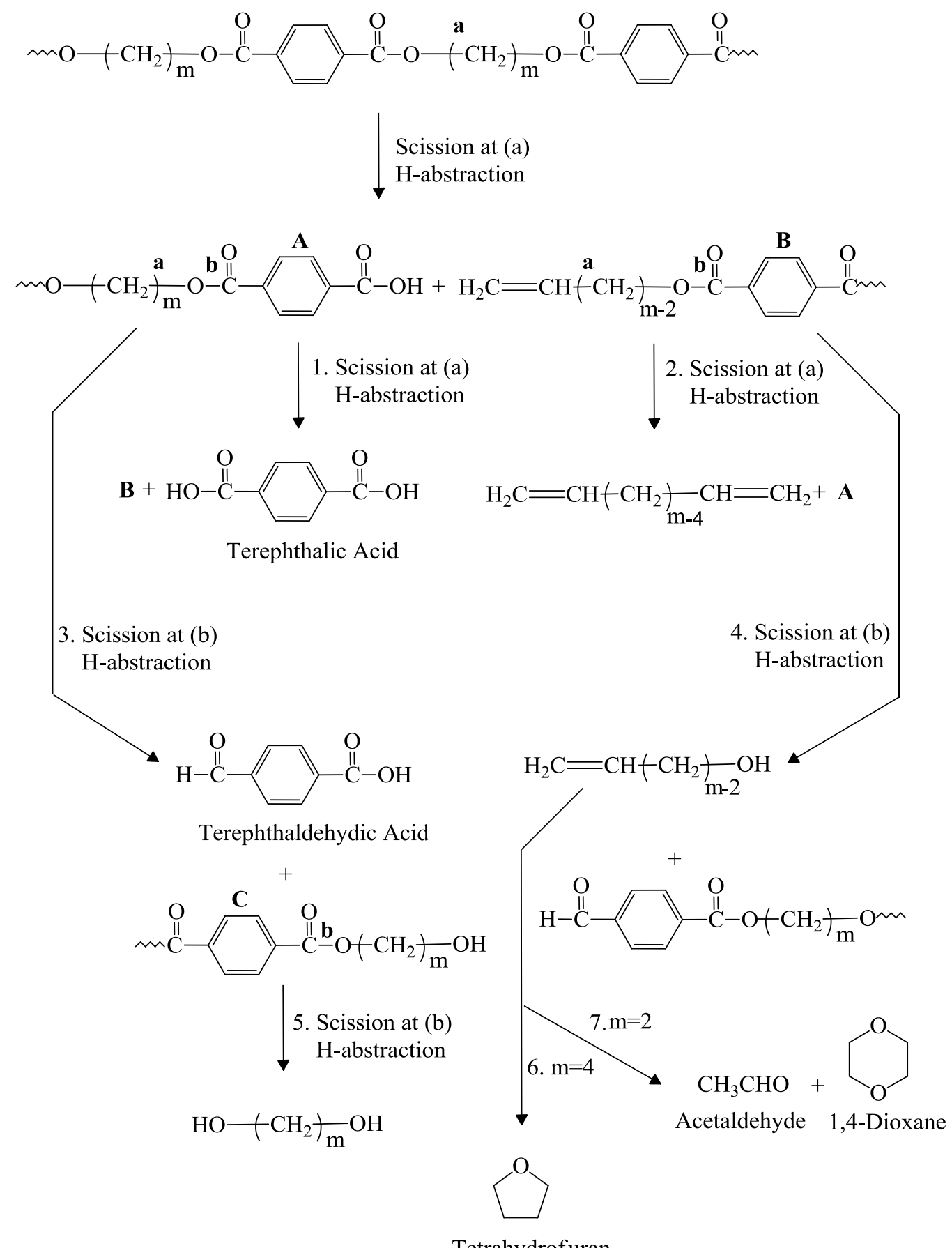

Tetrahydrofuran

Scheme 3: Basic homolytic mechanism for the thermal degradation of PET $(\mathrm{m}=2)$ as proposed by McNeill and Bounekhel ${ }^{[11]}$

\subsection{Thermal Gravimetric Analysis (TGA)}

TGA studies were carried out using a Perkin Elmer TGA (TGA7), controlled using Windows based software on a bench-top PC. All experiments were carried out using $10 \mathrm{mg}$ of sample under an inert atmosphere of helium. A heating profile of $50{ }^{\circ} \mathrm{C}$ to $800{ }^{\circ} \mathrm{C}$ was performed at a heating rate of 
$10{ }^{\circ} \mathrm{C} \min ^{-1}$ and all data was processed using Origin software. From the data obtained, the \% mass loss was recorded as a function of temperature and the onset temperatures of degradation were determined at $5 \%$ mass loss. The temperature values quoted from the TGA curves are rounded to the nearest integral value, with an error of $\pm 1{ }^{\circ} \mathrm{C}$.

\subsection{Thermal Volatilisation Analysis (TVA)}

TVA is a technique useful for studying the degradation behaviour of polymers that breakdown to give some proportion of volatile products when heated under vacuum. The system, built in-house, was based upon the apparatus and techniques originally described by I.C. McNeill and co-workers in $1966^{[14]}$ and developed subsequently. ${ }^{[15-17]}$

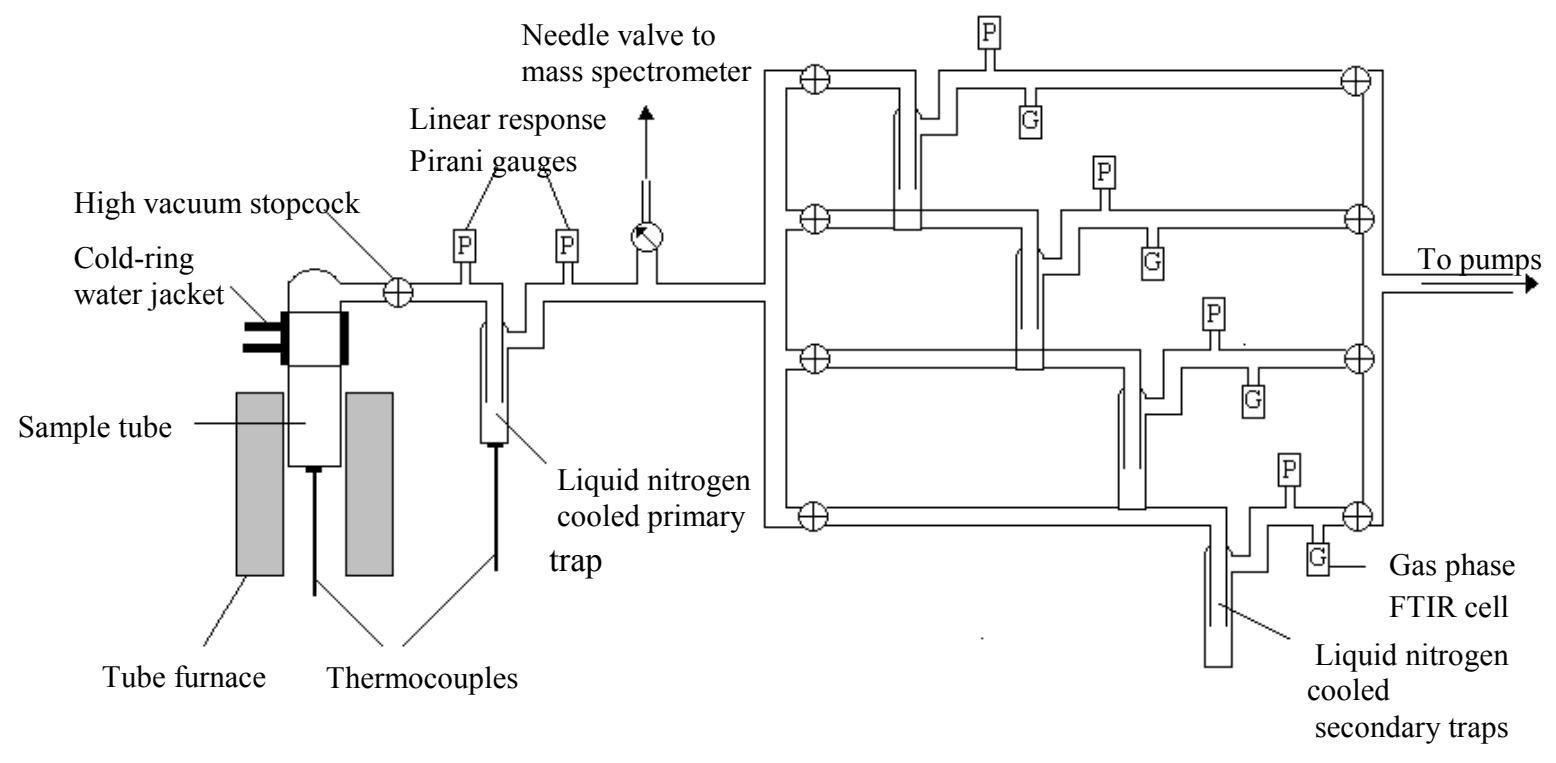

Figure 1: Schematic diagram of the TVA system

The TVA apparatus consists primarily of a glass sample chamber connected to a primary liquid nitrogen cooled sub-ambient trap and a series of secondary liquid nitrogen cooled cold traps, as illustrated in Figure 1. The entire system was pumped to a vacuum of $\sim 1 \times 10^{-4}$ Torr by the use of a two-stage rotary pump and an oil diffusion pumping system. As the sample was heated at a linear rate, using a programmable tube furnace, volatile materials could condense at the water jacket cooled 'cold ring' placed directly above the sample tube or the liquid nitrogen cooled primary trap. The water jacket cooled 'cold ring' condensed high boiling point degradation materials, which are not volatile under vacuum at ambient temperatures. In contrast, the volatile degradation species with lower boiling points were collected in a primary liquid nitrogen cooled sub-ambient trap, maintained at a temperature of $-196^{\circ} \mathrm{C}$. These 'condensable' fractions are volatile at room temperature but involatile 
at liquid nitrogen temperatures, hence collect within the primary sub-ambient trap. Linear response Pirani gauges, positioned at both the entrance and exit of the primary sub-ambient trap, enabled the evolution of both condensable and non-condensable volatiles to be continuously monitored as a function of pressure versus temperature. However, the volatile products collected in the cold ring fraction were not detected by Pirani gauges as they condense prior to exiting the degradation tube.

The low boiling point species, trapped within the liquid nitrogen cooled primary trap, could then be separated and isolated into four separate secondary traps. This process is known as differential distillation and simply involves heating the primary sub-ambient trap up to ambient temperatures. Pressure changes were monitored during the differential distillation by non-linear Pirani gauges as products were separated according to their volatility and collected for subsequent analysis. After separation, volatile degradation products were then transferred from the secondary traps into gas-phase cells for offline FTIR and GC-MS analysis. Throughout the entire thermal volatilisation procedure, the gas stream was continuously monitored at the exit of the primary sub-ambient trap by an online quadrupole mass spectrometer. This is particularly useful for the identification of non-condensable degradation products such as carbon monoxide and methane and condensable degradation products collected from the differential distillation procedure

The preferred sample type for TVA analysis was thin film samples cast from solution. $50 \mathrm{mg}$ of polyester chip was dissolved in $1 \mathrm{~mL}$ of hexafluoroisopropanol (HFIP). Upon dissolution, the sample solution was then transferred into a TVA tube and the solvent left to evaporate in standard laboratory conditions for a period of 24 hours. Prior to TVA analysis, the sample tube was placed in a vacuum oven for 4 hours at $10{ }^{\circ} \mathrm{C}$ above the polymer's $T_{g}$ to remove as much solvent as possible. Although residual solvent did still remain following sample preparation, the TVA curves presented illustrate only the degradation processes with the solvent separated from all other degradation products during the sub-ambient distillation process to avoid contamination of pressure curves.

A dynamic heating programme was applied to heat the sample of interest to $550{ }^{\circ} \mathrm{C}$ at a rate of $10{ }^{\circ} \mathrm{C} \mathrm{min}{ }^{-1}$. The sample was then isothermally held at $550{ }^{\circ} \mathrm{C}$ for a period of 30 minutes as the pressure was recorded at the cold trap to monitor continual cryogenic trapping of the evolved volatiles. Similarly, isothermal TVA studies were conducted by heating the sample of interest to the target temperature $\left(288,300\right.$ and $\left.320^{\circ} \mathrm{C}\right)$ at a rate of $10{ }^{\circ} \mathrm{C} \mathrm{min}^{-1}$ followed by an isothermal hold period of 60 minutes. Following the collection of volatile materials within the liquid nitrogen cooled primary trap, the sub-ambient distillation was then performed. This involved reheating the primary sub-ambient trap at a rate of $4{ }^{\circ} \mathrm{C} \min ^{-1}$ from $-196{ }^{\circ} \mathrm{C}$ to $40{ }^{\circ} \mathrm{C}$. The separated volatiles were subsequently analysed by a combination of MS, FTIR spectroscopy and GC-MS. 
MS analysis was performed using an online 1 - 300 amu Hiden single quadrupole RGA mass spectrometer operated in continual scan mode. During both TVA degradation and differential distillation, the instrument enabled online identification of both non-condensable and condensable volatile materials of a low molecular mass via continuous sampling of the gas stream. FTIR analysis of the collected degradation products was performed using a Perkin Elmer Spectrum 100 FTIR Spectrometer in transmission mode. The low boiling volatile species collected from TVA were directly analysed in the gas-phase using the gas-phase IR cells containing $\mathrm{NaCl}$ windows. The coldring fractions collected from TVA were cast from chloroform solution onto $\mathrm{NaCl}$ discs for analysis.

FTIR analyses were performed using a Perkin Elmer Spectrum 100 FTIR Spectrometer in transmission mode. The instrument was programmed to perform 32 scans over a wavenumber range of $4000-500 \mathrm{~cm}^{-1}$. Prior to analysis, a background run was performed with no cell in the sample area. Data was collected as a plot of \% transmission against wavenumber.

All GC-MS measurements were carried out using a Finnigan Thermoquest capillary column trace GC and Finnigan Polaris Quadrupole Mass Spectrometer. The capillary column consisted of a fused silica column with a silicone oil stationary phase and was programmed to perform a temperature ramp from 40 to $320{ }^{\circ} \mathrm{C}$ at a rate of $20{ }^{\circ} \mathrm{C} \mathrm{min}{ }^{-1}$. The carrier gas used was helium and the mass spectra were obtained over an m/z range of $30-600$. All cold-ring fractions analyzed by GC-MS were dissolved in chloroform and filtered using a syringe filter. These samples were then further diluted with chloroform prior to analysis. Any high boiling fractions collected from TVA were also initially dissolved in chloroform, however these fractions were treated as more dilute solutions and were not further diluted prior to GC-MS analysis. All solvents used throughout this research were obtained from Sigma-Aldrich Chemical Company. In addition to GC-MS analysis of the samples of interest, analysis was performed on solvent blanks to determine the background spectra obtained as a result of column contamination and impurities e.g. phthalates and/or plasticizers.

\section{RESULTS}

\subsection{Dynamic DSC Results}

Figure 2 illustrates the DSC thermograms obtained for the degradation of PET and PEN under nitrogen. Endothermic melting and degradation peaks can be observed in both DSC profiles. The spikes on both thermograms around the degradation region (typically above $400{ }^{\circ} \mathrm{C}$ ) are linked to the 
evolution of volatile species from the degrading samples, leading to sudden changes in the heat flow and movement of the sample pan on the sensor.

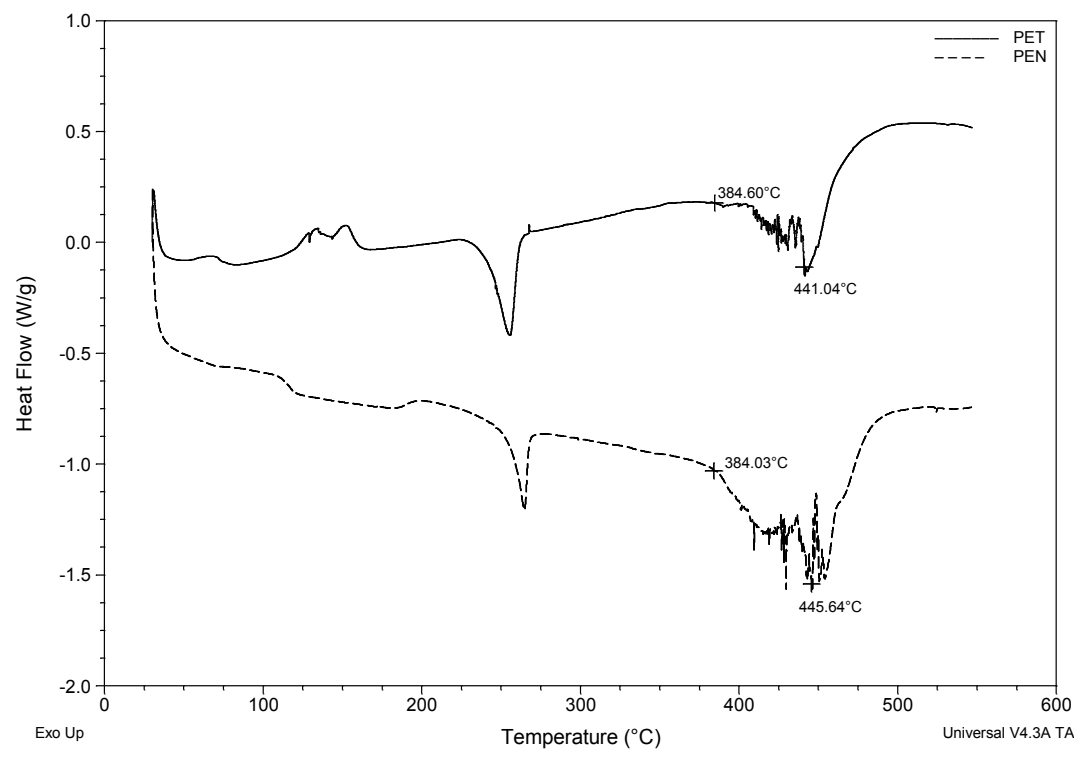

Figure 2: DSC thermograms of PET and PEN in $\mathrm{N}_{2}, 30-550{ }^{\circ} \mathrm{C}, 10{ }^{\circ} \mathrm{C} \mathrm{min}^{-1}$

Serious endothermic degradation of PET occurs from approximately $385{ }^{\circ} \mathrm{C}$ onwards, where the major endothermic peak can be observed. The minimum heat flow, corresponding to this one major degradation event, was observed at $441{ }^{\circ} \mathrm{C}$. Similarly, serious endothermic degradation of PEN commenced at $384{ }^{\circ} \mathrm{C}$ and the minimum heat flow, corresponding to this endothermic degradation event was observed at $446^{\circ} \mathrm{C}$.

\subsection{Dynamic TGA Results}

The thermogravimetry and differential thermogravimetry curves for the non-oxidative degradation of PET and PEN are shown in Figure 3. For degradation under helium, comparison of the TGA traces revealed only small differences in the mass loss behaviour of PET and PEN. 


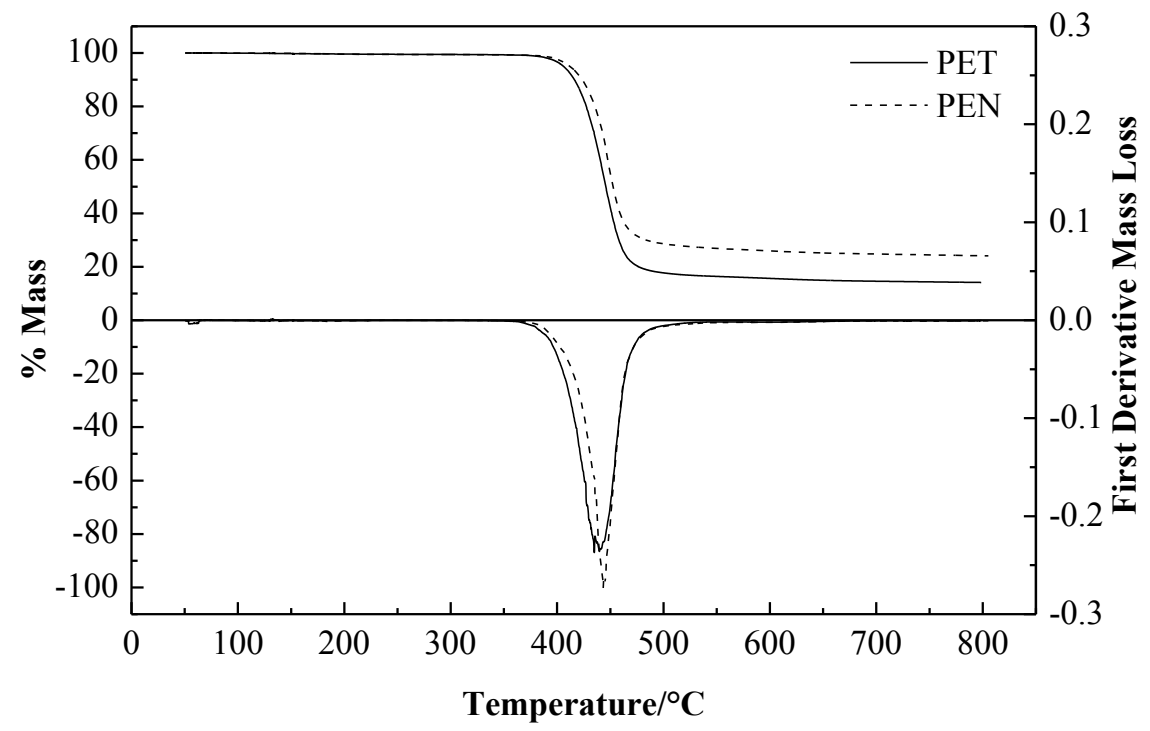

Figure 3: Thermogravimetry and differential thermogravimetry curves of PET and PEN in helium, $30-800{ }^{\circ} \mathrm{C}, 10{ }^{\circ} \mathrm{C} \min ^{-1}$

Both PET and PEN appear to undergo only one significant mass loss step in an inert environment. However, the temperature at which this mass loss step occurs differs. For PET, significant mass loss (i.e. $5 \%$ mass loss) is not evident until $406{ }^{\circ} \mathrm{C}$. Above this temperature, one significant mass loss event occurs stretching to approximately $520^{\circ} \mathrm{C}$. As seen in the differential thermogravimetry curve, the maximum rate of mass loss for PET is observed at $441{ }^{\circ} \mathrm{C}$. This maximum mass loss is thought to be due to thermal degradation of the polymer backbone i.e. chain scission of the ester bonds. Finally, at temperatures above $520{ }^{\circ} \mathrm{C}$, the thermogravimetric curve of PET indicates a slow continuous mass loss up to $800{ }^{\circ} \mathrm{C}$. $14 \%$ of the original mass of PET was found to remain after TG analysis.

In contrast to PET, a delay in the initial release of volatiles was observed for PEN. Significant mass loss of PEN is not evident until $412{ }^{\circ} \mathrm{C}$. The major mass loss event in PEN occurs between $412{ }^{\circ} \mathrm{C}$ and $520{ }^{\circ} \mathrm{C}$ and the maximum rate of mass loss from the differential thermogravimetry curve can be observed at $443{ }^{\circ} \mathrm{C}$. A slow continuous mass loss in PEN then follows, from $520{ }^{\circ} \mathrm{C}$ up to $800{ }^{\circ} \mathrm{C}$, yielding a final residue of $24 \%$. Finally, it is noteworthy that the overall $\%$ mass of carbonaceous residue remaining from the degradation of PEN is significantly increased in comparison to PET. This is not entirely surprising as the majority of the carbonaceous residue originates from graphitization of aromatic sequences. The overall $\%$ mass fraction of aromatic sequences present in the repeat units of PET and PEN are $41 \%$ and $52 \%$ respectively. This higher $\%$ mass fraction of aromatic sequences in PEN therefore results in an increase in the overall carbonaceous residue.

The DSC and TGA results presented in Figures 2 and 3 appear to correlate well. Both techniques indicate that PET and PEN undergo only one major thermal degradation process, in an inert 
atmosphere, with maximum degradation activity occurring above $440{ }^{\circ} \mathrm{C}$ for both PET and PEN. The temperatures of degradation for PEN were marginally increased, emphasising the increased thermal stability of PEN over its terephthalate counterpart.

\subsection{Thermal Volatilisation Studies}

\subsubsection{Degradation Profiles for PET and PEN}

From DSC and TGA studies of PET and PEN, it is apparent that the thermal degradation behaviour of both polymers is similar. However, to gain further insight into the processes involved in the thermal degradation of both polyesters, thermal volatilisation analysis was performed. TVA is a powerful tool useful for studying the degradation behaviour of polymers that breakdown to give some proportion of volatile products when heated under vacuum. The resultant thermogram profiles for PET and PEN are illustrated in Figure 4. Table 1 presents both the furnace and corresponding sample temperature for each major degradation event.

In PET, the evolution of volatile species starts at $365{ }^{\circ} \mathrm{C}$ where a rapid increase in pressure is observed. The peak maximum for the evolution of volatile species in PET can be observed at $420{ }^{\circ} \mathrm{C}$. In contrast, the initial evolution of volatile species in PEN is not evident until a higher temperature of approximately $380^{\circ} \mathrm{C}$. Similarly, the peak maximum for the evolution of volatile species in PEN can be observed at a slightly higher temperature of $433{ }^{\circ} \mathrm{C}$. This increased thermal stability is thought to be a result of the enhanced delocalisation of charge across the naphthalene ring units in PEN, increasing the overall stability of the ester linkages within the polymer chains.

\begin{tabular}{|c|c|c|}
\hline & Furnace Temperature ${ }^{\mathbf{0}} \mathbf{C}$ & Sample temperature ${ }^{\mathbf{0}} \mathbf{C}$ \\
\hline PET & 386 & 365 \\
\hline Onset of volatile evolution & 441 & 420 \\
\hline $\begin{array}{c}\text { Peak 1 maximum rate of } \\
\text { volatile evolution }\end{array}$ & 399 & 380 \\
\hline PEN & 452 & 433 \\
\hline Onset of volatile evolution & 468 & 448 \\
\hline $\begin{array}{c}\text { Peak 1 maximum rate of } \\
\text { volatile evolution } \\
\text { Peak 2 maximum rate of } \\
\text { volatile evolution }\end{array}$ & & \\
\hline
\end{tabular}

Table 1: Key TVA degradation temperatures for PET and PEN 
(a)

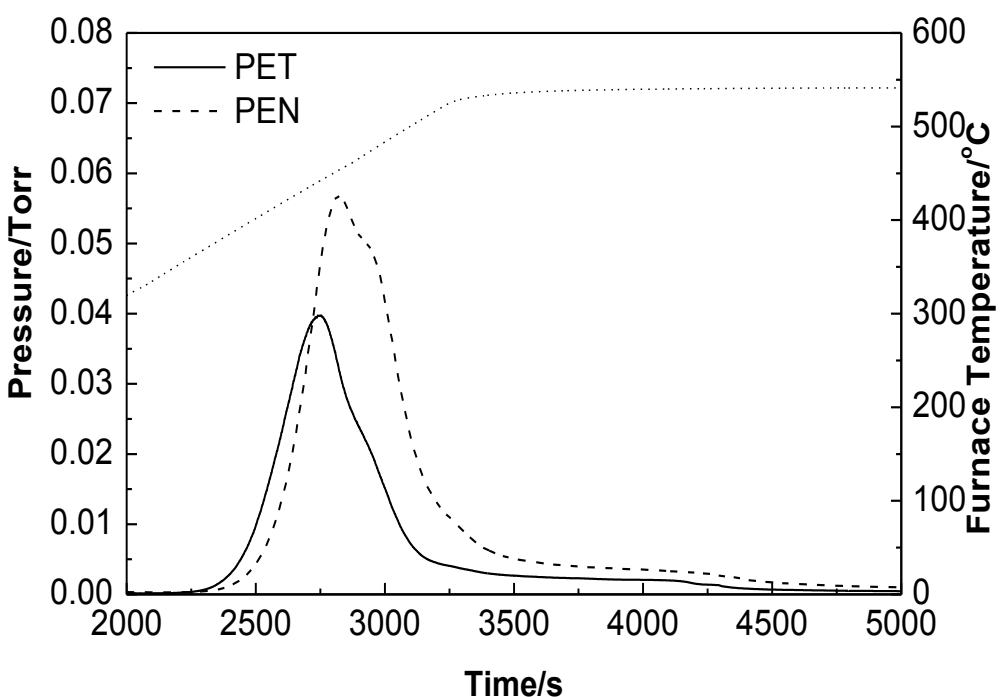

(b)

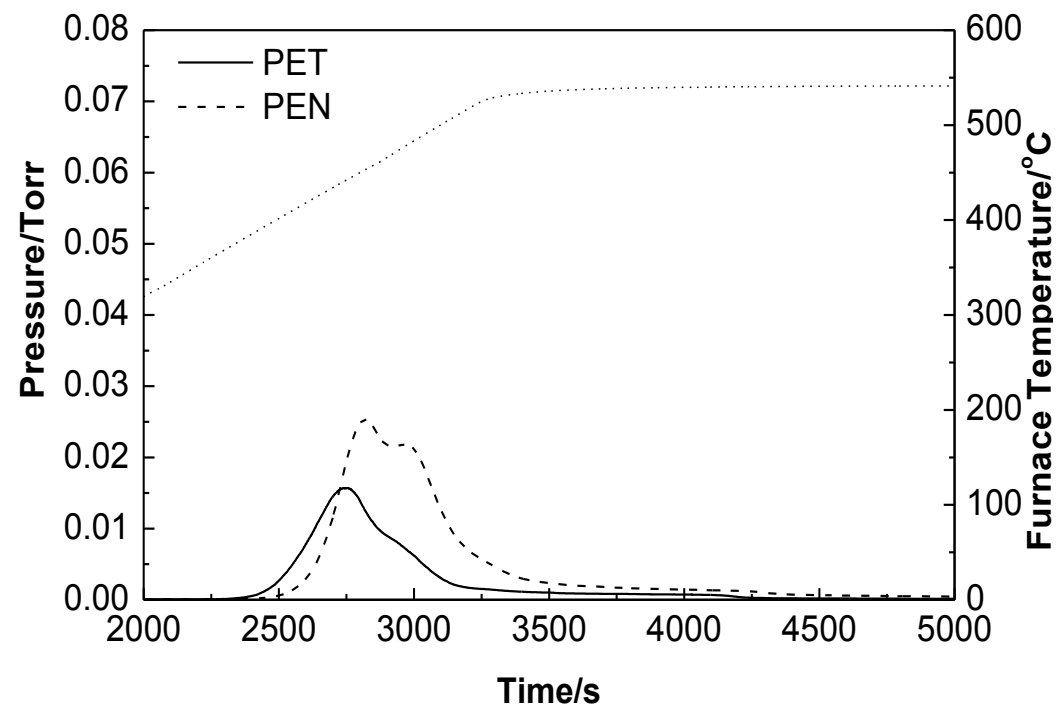

Figure 4: TVA thermograms showing total evolution of (a) total volatile species and (b) noncondensable species for PET and PEN, furnace temperature $/{ }^{\circ} \mathrm{C}$ also illustrated

Almost $50 \%$ of the total volatile species detected in PET and PEN are non-condensable species. These non-condensable degradation species were detected using real-time online mass spectrometry and were found to consist mainly of carbon monoxide for both PET and PEN. Traces of methane and hydrogen were also detected for both polymers, as illustrated in Figure 5, using the mass spectrometer in multiple ion detection mode. 
(a)

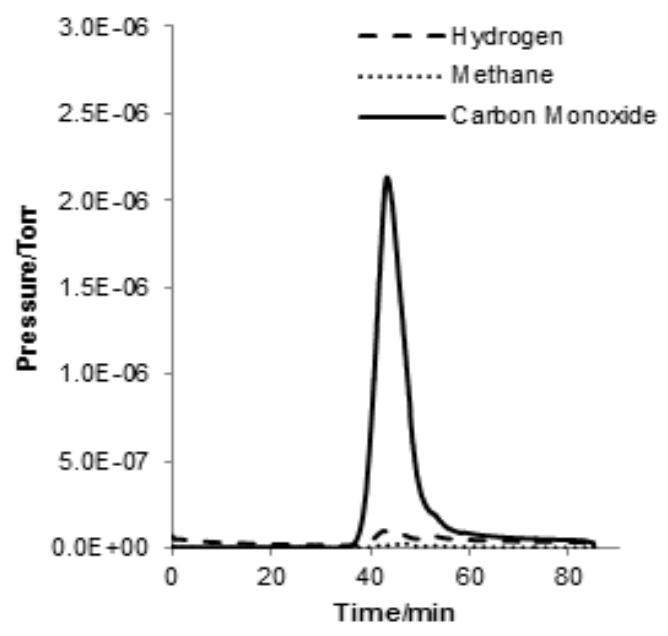

(b)

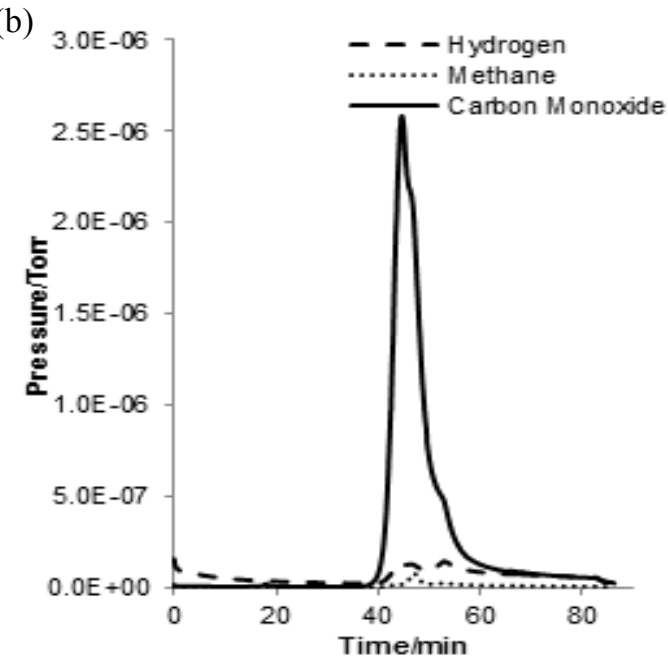

Figure 5: Non-condensable product distribution in (a) PET and (b) PEN

A small shoulder on the degradation curve of PEN at $448{ }^{\circ} \mathrm{C}$, suggests the possibility of a two-step degradation process occurring in PEN, in contrast to one major degradation process in PET. This is also evident in the mass spectrum for the evolution of non-condensable volatiles in PEN. In order to determine if this two-step degradation process was valid or simply a diffusion limited effect, isothermal TVA studies were performed at temperatures of 400,450 and $500{ }^{\circ} \mathrm{C}$, encompassing either side of the small shoulder on the degradation curve. However, the degradation products, at all temperatures, were found to be identical to those reported below for complete degradation up to $550{ }^{\circ} \mathrm{C}$. Only the relative amounts of degradation products were found to vary with temperature. This demonstrates that the mechanism of degradation does not differ on either side of the small shoulder on the degradation curve of PEN. Instead, it is thought that this small shoulder is due to the increased melt-viscosity of PEN, inhibiting the diffusion of volatile degradation products from the polymer melt.

\subsubsection{Sub-Ambient Distillation Data for PET and PEN}

During the sub-ambient distillation of the degradation products from PET and PEN, four separate fractions were collected from both polymers. The sub-ambient distillation profile, illustrated in Figure 6 , provides a qualitative indication of the distribution of condensable volatile species produced during degradation. Only small differences were evident in the product distribution, highlighting strong similarities in the thermal degradation of PET and PEN. 


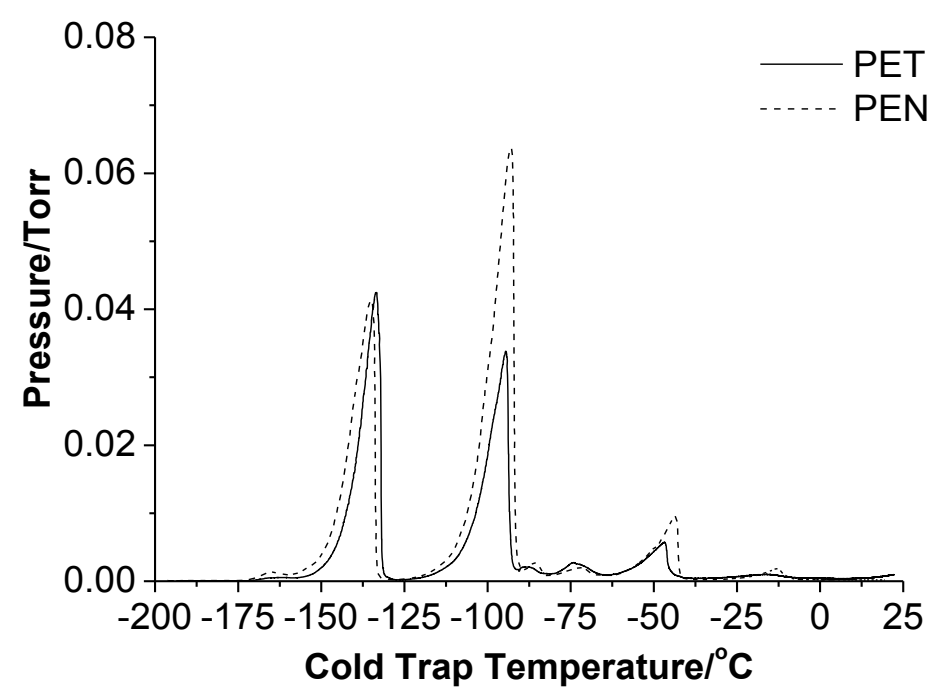

Figure 6: Sub-ambient TVA curve for degradation products of PET and PEN

\subsubsection{PET and PEN Degradation Products}

The TVA sub-ambient distillation curves, shown in Figure 6, highlight the strong similarities in the thermal degradation of PET and PEN. Table 2 illustrates the degradation products collected from PET and PEN. The composition of degradation products were identified using IR, online-MS and GC-MS analysis.

\begin{tabular}{|c|c|c|}
\hline Fraction & Temperature range collected & Major degradation product(s) \\
\hline PET (1) & $-196{ }^{\circ} \mathrm{C}$ to $-125^{\circ} \mathrm{C}$ & Carbon dioxide, Ethylene, Acetylene \\
\hline PEN (1) & $-192{ }^{\circ} \mathrm{C}$ to $-119{ }^{\circ} \mathrm{C}$ & Carbon dioxide, Ethylene, Acetylene \\
\hline PET (2) & $-124{ }^{\circ} \mathrm{C}$ to $-90^{\circ} \mathrm{C}$ & Acetaldehyde \\
\hline PEN (2) & $-118^{\circ} \mathrm{C}$ to $-82^{\circ} \mathrm{C}$ & Acetaldehyde \\
\hline PET (3) & $-89{ }^{\circ} \mathrm{C}$ to $-37^{\circ} \mathrm{C}$ & Benzene, Toluene, Water \\
\hline PEN (3) & $-81{ }^{\circ} \mathrm{C}$ to $-40{ }^{\circ} \mathrm{C}$ & Wenzaldehyde, Benzoic acid \\
\hline PET (4) & $-36^{\circ} \mathrm{C}$ to $40^{\circ} \mathrm{C}$ & Naphthalene, Methyl naphthalene \\
\hline PEN (4) & $-39{ }^{\circ} \mathrm{C}$ to $40^{\circ} \mathrm{C}$ & \\
\hline
\end{tabular}

Table 2: Major sub-ambient distillation products collected from the degradation of PET and PEN

The first two fractions, collected from PEN, were identical to those found in PET. Fraction 1 from PET and PEN was found to consist mainly of carbon dioxide with traces of ethylene and acetylene. Acetaldehyde was identified by MS and FTIR in fraction 2 from both polyesters. The gas-phase FTIR spectra for carbon dioxide and acetaldehyde are presented in Figure 7. The presence of such large 
amounts of carbon dioxide and acetaldehyde, identified from fractions 1 and 2, highlight the extent of chain scission within the polyester backbone during thermal degradation of both PET and PEN.
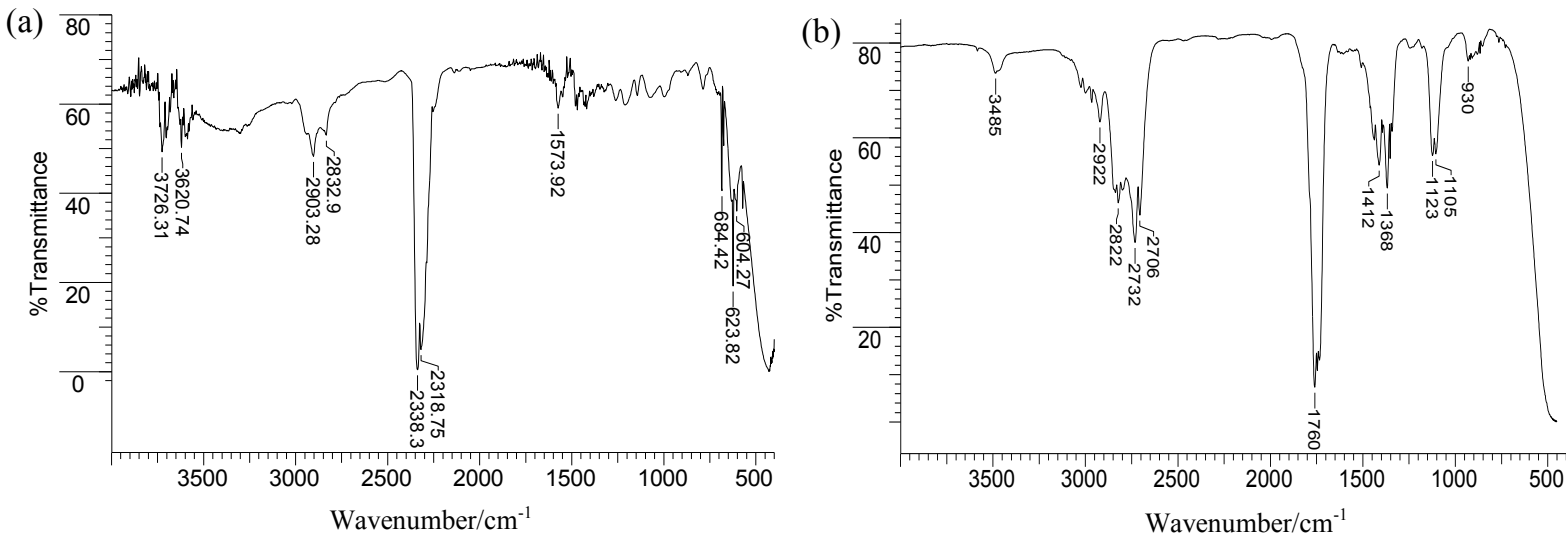

Figure 7: FTIR spectrum of (a) carbon dioxide, ethylene and acetylene - PET/PEN fraction 1 and (b) acetaldehyde - PET/PEN fraction 2

During the sub-ambient distillation, online mass spectrometry was of key importance in the identification of degradation species present in fractions 3 and 4 from PET. This was due to the predominantly weaker IR spectra obtained, in contrast to fractions 1 and 2. The mass spectra for PET fraction 3, illustrated in Figure 8, highlight the presence of benzene, toluene and water. This was confirmed by offline IR spectrum from the presence of aromatic $\mathrm{C}-\mathrm{H}$ stretching observed around $1600 \mathrm{~cm}^{-1}$ and one broad O-H band at $3401 \mathrm{~cm}^{-1}$. Stretching vibrations can also be seen at $1733 \mathrm{~cm}^{-1}$ and indicate the presence of an aromatic aldehyde. This aldehyde is most likely to be benzaldehyde, the bulk of which was collected in fraction 4.

From online mass spectrometry, fraction 4 from PET was found to consist of benzaldehyde and trace amounts of benzoic acid. Trace quantities of other high molar mass aromatic ketones and esters were also thought to exist. However due to the small quantities and overlap in the mass spectra, positive identification of these species was difficult. Similarly, FTIR analysis was inconclusive but additional solvent trapping of the volatile product in a secondary limb enabled GC-MS analysis to be performed on fraction 4 from PET. Figure 9 illustrates the GC-MS chromatogram for PET fraction 4 with identification of the minor degradation products presented in Table 3. GC-MS analysis confirmed the presence of both major degradation products benzaldehyde $(\mathrm{m} / \mathrm{z}=106)$ and benzoic acid $(\mathrm{m} / \mathrm{z}=122)$. Due to the improved detection limits of GC-MS, toluene, ethyl benzene, 4-formylbenzoic acid and biphenyl were also detected. The presence of such degradation products in fraction 4 from PET indicates extensive fragmentation of the polyester chain, most likely to be a result of radical degradation processes. 
(a)

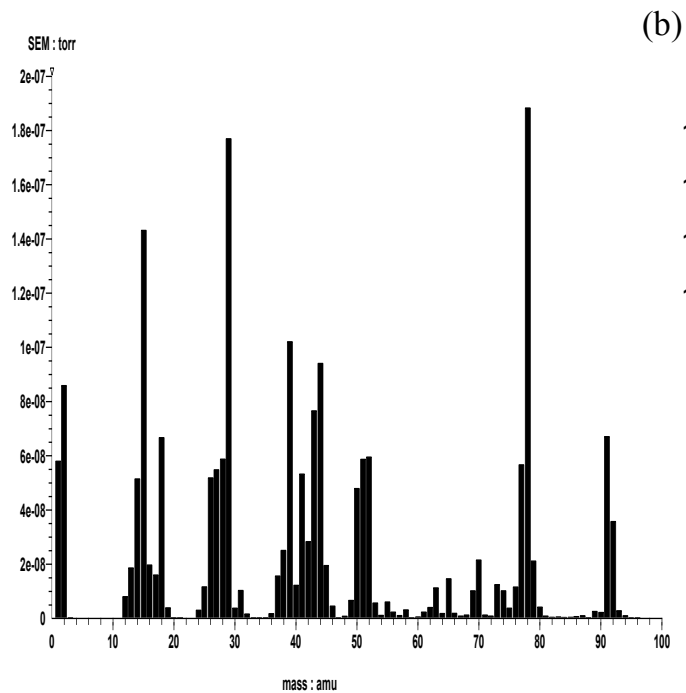

(b)

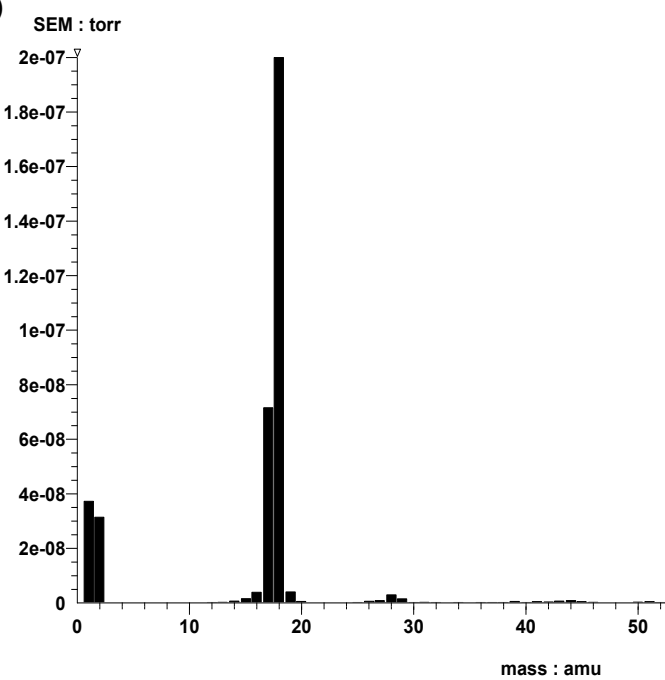

Figure 8: Mass spectrum of (a) benzene and toluene and (b) water - PET fraction 3

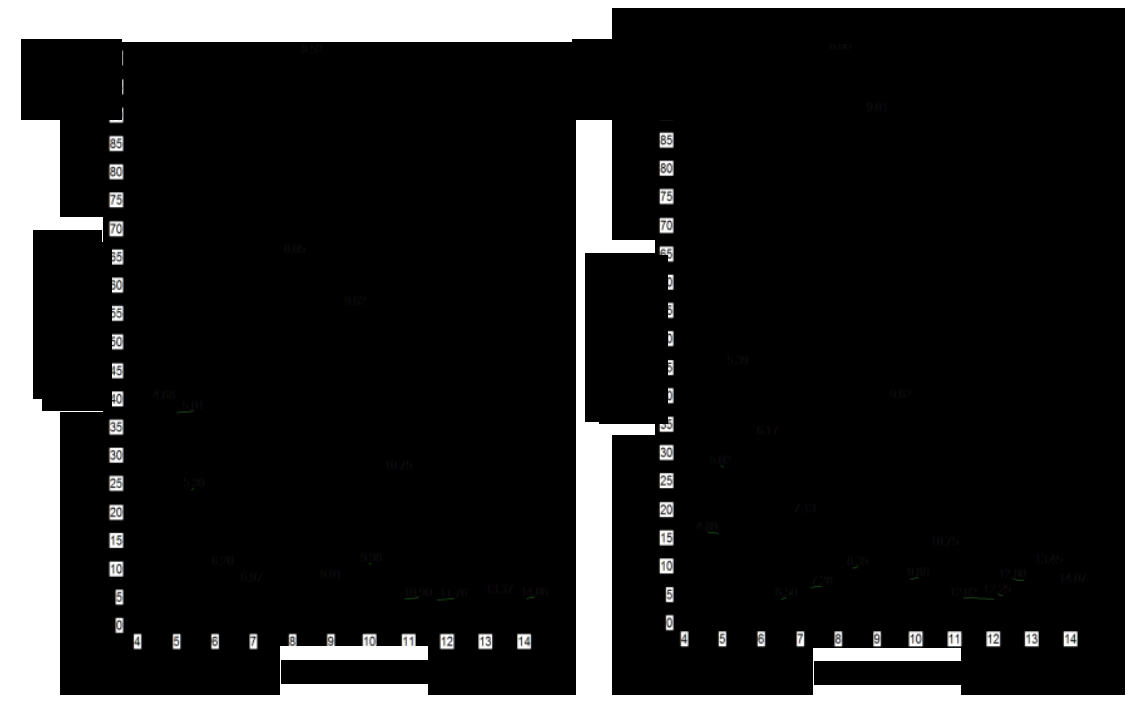

Figure 9: GC-MS total ion chromatograms for fraction 4 from (a) PET and (b) PEN

\begin{tabular}{|c|c|}
\hline Retention Time $/ \mathbf{m i n}$ & Degradation Product \\
\hline 4.68 & Toluene \\
\hline 5.84 & Ethyl benzene \\
\hline 7.95 & Benzaldehyde \\
\hline 8.52 & Benzoic acid \\
\hline 8.81 & 4-Formyl benzoic acid \\
\hline 10.44 & Biphenyl \\
\hline
\end{tabular}

Table 3: Minor products from PET fraction 4 PET identified by GC-MS 
In fractions 3 and 4, the degradation products were found to differ between PET and PEN. This is due to distinct differences in volatility between benzene and naphthalene. Degradation products from PEN, containing naphthalene rings, have increased molar mass and are therefore less volatile. Fraction 3 in PEN was therefore found to consist only of water, with less volatile, higher molar mass fragments, such as naphthalene and methyl naphthalene identified in fraction 4. Solvent trapping of the volatile products in a secondary limb enabled GC-MS analysis to be performed on fraction 4 from PEN, as illustrated in Figure 9. GC-MS analysis confirmed the presence of both naphthalene and methyl naphthalene at retention times of 9.01 and 9.86 minutes, respectively.

\subsubsection{Cold Ring Fractions of PET and PEN}

The cold ring fractions of PET and PEN, containing high boiling point degradation products condensable at room temperature, were both found to consist of a mixture of white powdery solid and a yellow coloured solid. As the material was extracted into chloroform it became apparent that the majority of the material was insoluble. The material was dissolved in a number of other common laboratory solvents with little success, indicating that the bulk of the cold ring fraction of PET and PEN was likely to consist of oligomeric polyester. The IR spectrum, obtained from the cold ring fractions of PET and PEN, are illustrated in Figure 10. Table 4 displays the IR bands observed on analysis of the both cold ring fractions with the general assignment for each absorption band.

(a)

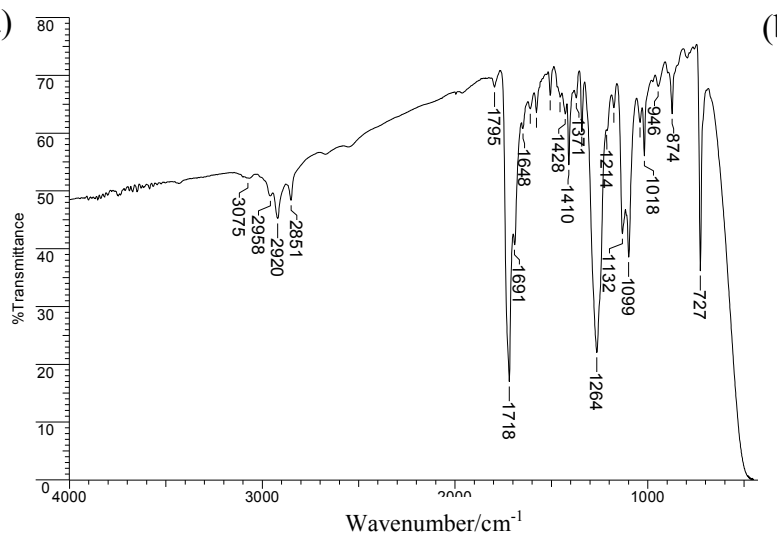

(b)

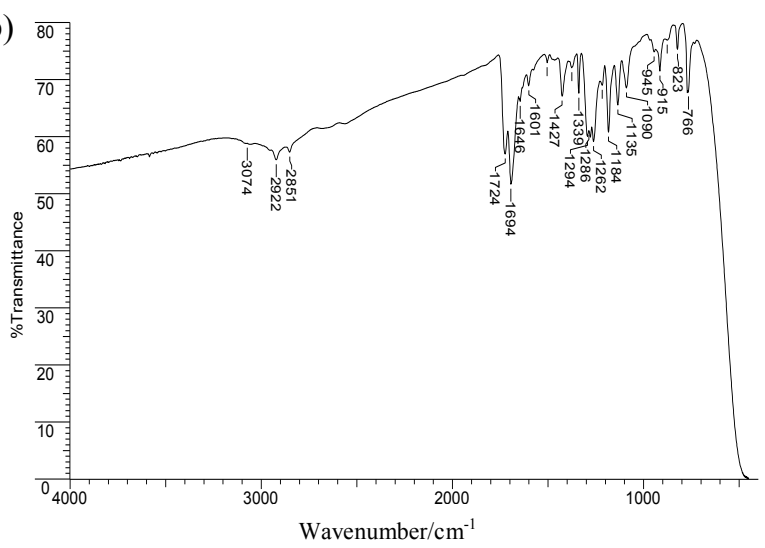

Figure 10: IR spectrum of (a) PET and (b) PEN cold ring fractions 


\begin{tabular}{|c|c|c|}
\hline \multicolumn{2}{|c|}{ Wavenumber $/ \mathrm{cm}^{-1}$} & Absorption mode \\
\hline PET & PEN & \\
\hline 3075 & 3074 & Aromatic C-H stretching \\
\hline $2958,2920,2851$ & 2922,2851 & Aliphatic C-H stretching (saturated C-H) \\
\hline 1795 & - & $\mathrm{C}=\mathrm{O}$ absorption of vinyl ester \\
\hline 1718 & 1724 & $\mathrm{C}=\mathrm{O}$ absorption of ester \\
\hline 1691 & 1694 & $\mathrm{C}=\mathrm{O}$ absorption of aryl carboxylic acid \\
\hline $1648-1342$ & $1646-1339$ & Aromatic skeletal C-H stretching \\
\hline 1264,1132 & $1294,1262,1184$ & $\mathrm{C}(\mathrm{O})$-O stretching of ester \\
\hline $1176,1099,1018$ & $1217,1135,1090$ & $\begin{array}{c}\text { Bands in skeletal region indicate 1,4-substitution of } \\
\text { aromatics }\end{array}$ \\
\hline 948 & 915 & $\mathrm{O}-\mathrm{CH}_{2}$ stretching of EG \\
\hline 874 & 823 & $\begin{array}{c}\text { C-H out-of-plane deformations of para-substituted } \\
\text { benzene ring }\end{array}$ \\
\hline 727 & 766 & $\begin{array}{l}\text { Out of plane deformations of two carbonyl substituents } \\
\text { on aromatic ring }\end{array}$ \\
\hline
\end{tabular}

Table 4: IR peak assignments from TVA cold ring fraction of PET and PEN ${ }^{[18,19,20]}$

The IR results presented highlight the presence of a mixture of species within the PET cold ring fraction containing acidic, ester and vinyl functionalities. However, the predominant species, in terms of the relative intensity of the IR peaks, was the PET repeat unit and terephthalic acid. PET is most likely to be encountered as short oligomeric PET, due to the chain scission processes occurring during thermal degradation. Similar to PET, the results indicate the presence of mainly oligomers within the cold ring fraction of PEN. Unfortunately, due to the weak intensities of the absorption bands in the spectrum, the identification of other degradation species proved difficult.

In addition to IR, the soluble component of the cold ring fractions of PET and PEN were analysed by GC-MS, as illustrated in Figure 11. In agreement with the IR results already presented, the GC-MS analysis of the cold ring fractions of both PET and PEN indicate the presence of different degradation species containing acidic, aldehydic, ester and vinyl functionalities due to the extent of chain fragmentation. Binaphthalene was also identified from the cold ring fraction of PEN. In contrast to the degradation species collected in fraction 4 for PET and PEN, the degradation products found within the cold ring fractions were of a higher molecular weight and thus reduced volatility as would be expected. Table 5 highlights the variety of degradation species identified from GC-MS analysis of the PET and PEN cold ring fractions. 


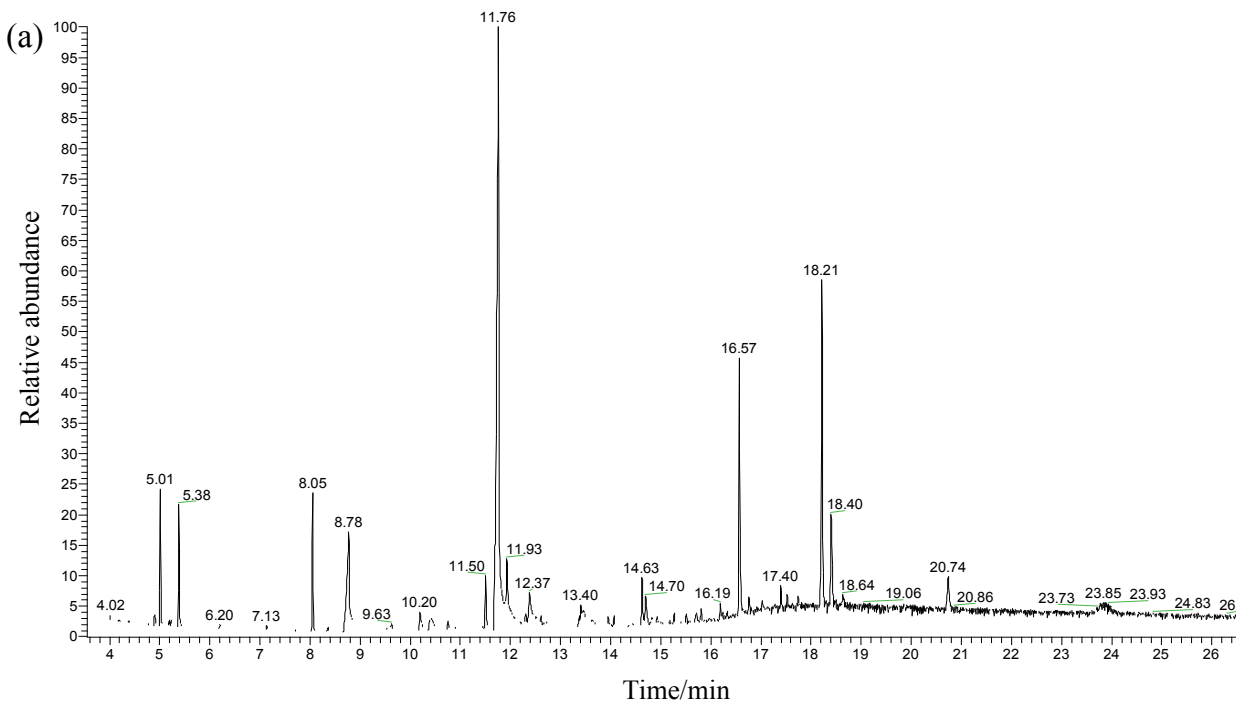

(b)

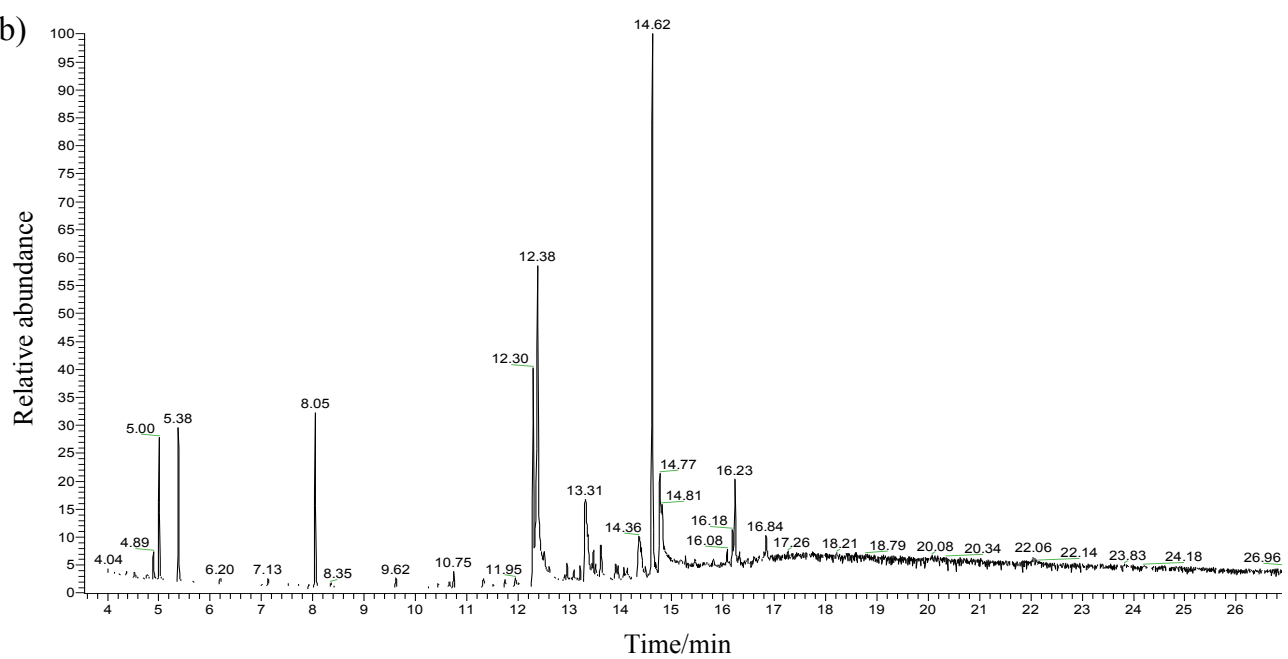

Figure 11: GC-MS total ion chromatograms for cold ring fractions from (a) PET and (b) PEN 


\begin{tabular}{|c|c|c|}
\hline Polyester & Retention Time/min & Degradation Product \\
\hline PET & 8.78 & Benzoic acid \\
\hline PET & 10.20 & Ethyl benzoate \\
\hline PET & 10.40 & Vinyl benzoate \\
\hline PET & 11.50 & Ethenyl 4-formylbenzoate \\
\hline PET & 11.72 & 4-Formyl benzoic acid \\
\hline PET & 11.96 & 4-(Ethoxycarbonyl) benzoic acid \\
\hline PEN & 11.95 & Naphthalene-2,6-dicarbaldehyde \\
\hline PEN & 12.30 & Naphthalene-2-carboxylic acid \\
\hline PEN & 12.36 & 6-Formylnaphthalene-2-carboxylic acid \\
\hline PEN & 12.51 & Methyl naphthalene-2-carboxylate \\
\hline PEN & 13.03 & Ethenyl 6-formylnaphthalene-2-carboxylate \\
\hline PEN & 14.62 & Diethenyl naphthalene-2,6-dicarboxylate \\
\hline PEN & 16.08 & Binaphthalene \\
\hline PEN & $16.23,16.84$ & \\
\hline
\end{tabular}

Table 5: Degradation products from cold rings fractions of PET and PEN, identified by GC-MS

\subsection{Discussion of the Thermal Degradation Mechanisms of PET and PEN}

DSC, TGA and TVA results all indicate that under inert conditions both PET and PEN undergo one major degradation process. This is most likely to involve the thermal cleavage of ester bonds in the polymer backbone resulting in the formation of vinyl ester and carboxylic acid end groups as shown in Scheme 2 for PET. This primary thermal degradation reaction is thought to be identical for both PET and PEN.

On the basis of the TVA results presented, it can be concluded that PET thermally degrades above temperatures of $365{ }^{\circ} \mathrm{C}$, subsequently leading to the release of volatile species. Of the volatile species evolved, those condensable within the cold ring fraction comprise of mainly PET oligomers, terephthalic acid and a number of mono- and di-substituted chain fragments constituting acidic, aldehydic, ester and vinyl functional groups. The volatile degradation species, capable of condensing at $-196{ }^{\circ} \mathrm{C}$, were positively identified as carbon dioxide, ethylene, acetylene, acetaldehyde, toluene, benzene, water, benzaldehyde and benzoic acid. Large amounts of carbon monoxide were also detected as non-condensable gases alongside traces of methane and hydrogen. These observations are consistent with those of McNeill and Bounekhel ${ }^{[11]}$ outlined in Scheme 3 and provide a good 
explanation for the continuous formation of carbon monoxide and carbon dioxide. This homolytic mechanism accounts for the wide range of degradation products observed from TVA studies of PET at temperatures ranging from $300-500{ }^{\circ} \mathrm{C}$. McNeill et al. believe that only a homolytic mechanism can explain the whole range of degradation products formed, in particular the large quantities of carbon monoxide and carbon dioxide formed throughout the main temperature range of decomposition. If the main chain degradation process of PET were to proceed via a non-homolytic degradation mechanism, continuous formation of carbon monoxide and carbon dioxide would only be observed at the highest degradation temperatures. However, from the results presented above, copious amounts of both carbon monoxide and carbon dioxide were formed alongside other degradation products at a range of degradation temperatures between 400 and $550{ }^{\circ} \mathrm{C}$. Although Zimmermann ${ }^{[12]}$ argues that a homolytic degradation reaction is not possible, as it is not inhibited by free radical trapping agents, the mechanism thought to occur involves only homolysis followed by $\mathrm{H}$-abstraction, mainly by disproportionation of the pair of radicals formed as a result of homolytic scission. Only chain reaction mechanisms are reported to be inhibited by radical trapping reagents.

The predominant reaction in the thermal degradation of PET is therefore likely to involve homolytic bond scissions in the polymer backbone as illustrated in Schemes 2 and 3. The resultant radicals can then abstract hydrogen from elsewhere in the system or undergo disproportionation reactions with other radicals formed as a result of homolytic scission. These chain scission reactions account for the products identified, in particular the significant formation of carbon monoxide and carbon dioxide. Variations in this basic homolytic degradation scheme proposed in Scheme 3 can be derived resulting in the formation of a variety of products often containing alkyl, acidic, aldehydic or vinyl groups at one or both ends of the polymer chain. Carbon monoxide and carbon dioxide are continuously formed by homolytic degradation reactions at the alkyl-oxygen or acyl-oxygen link respectively, followed by $\mathrm{H}$-abstraction by the radicals formed.

For PEN, both the temperatures of degradation and product distribution suggest that the polymer degrades in much the same fashion as PET, with the primary step being the thermal cleavage of ester bonds in the polymer backbone resulting in the formation of vinyl ester and carboxylic acid end groups as shown in Scheme 2 for PET. PEN does have a higher degradation onset temperature of $380{ }^{\circ} \mathrm{C}$, in comparison to $365{ }^{\circ} \mathrm{C}$ for PET. This reflects the enhanced delocalisation of charge across the naphthalene ring units in PEN, increasing the stability of the ester linkages and thus the overall thermal stability of the polymer. Identical homolytic chain scission reactions to those in PET are thought to occur during the thermal degradation of PEN, leading to the formation of volatile degradation products such as ethylene, acetylene, acetaldehyde, naphthalene and methyl naphthalene alongside large quantities of carbon monoxide and carbon dioxide. High molar mass degradation products including oligomeric PEN and degradation fragments containing alkyl, acidic, aldehydic, 
ester and vinyl functionalities on the naphthalene rings were also identified in the cold ring fraction from PEN, and similar in end group nature to those observed for PET. Therefore, it is possible to suggest an essentially similar mechanism of decomposition for both polyesters. Scheme 4 summarises the homolytic bond scissions likely to occur during the thermal degradation of PEN.

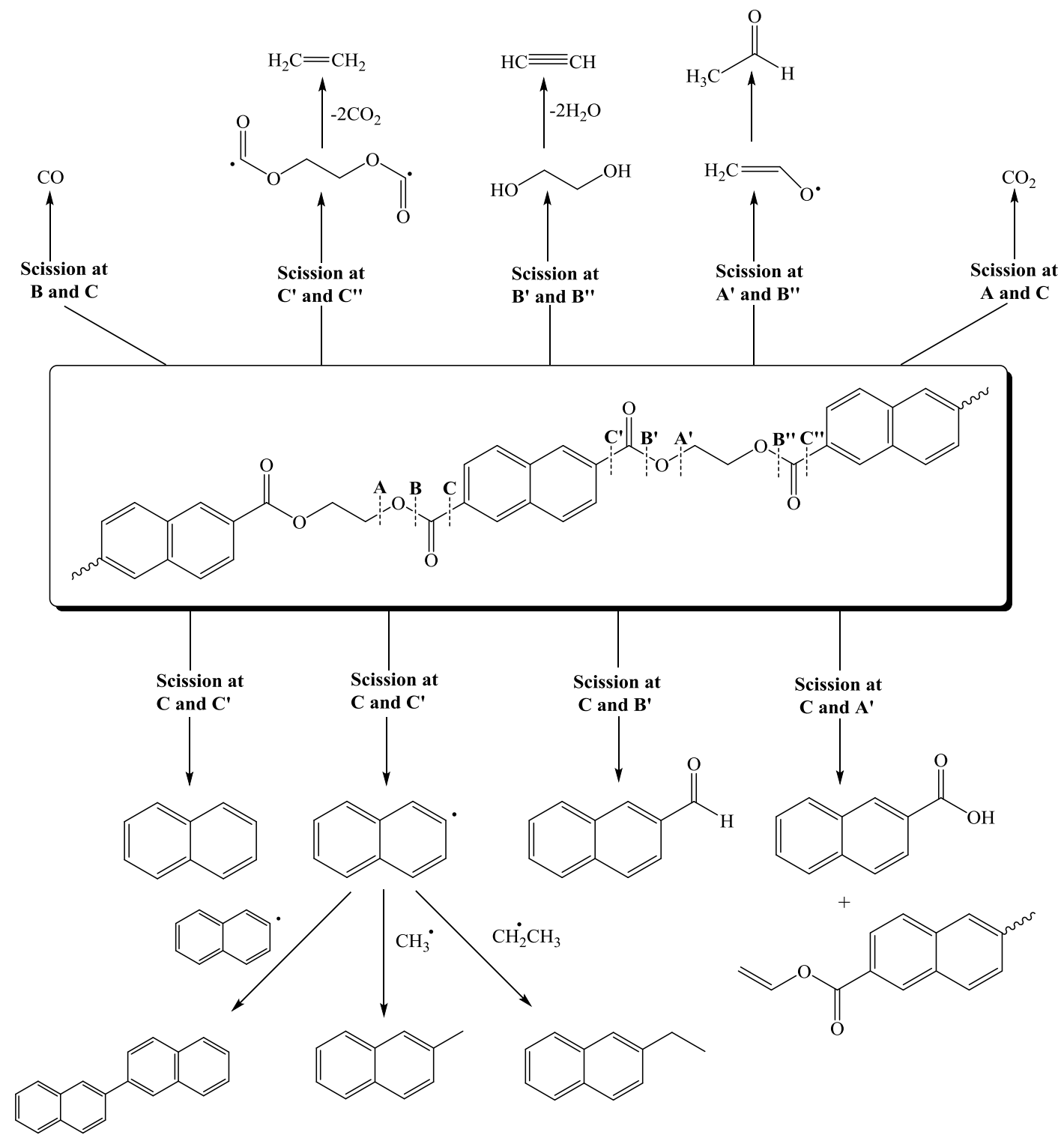

Scheme 4: Basic homolytic mechanism for the thermal degradation of PEN

\subsection{Thermal Volatilisation Studies at Processing Temperatures}

\subsubsection{Degradation Profiles for PET and PEN}


To study the degradation at temperatures more relevant to thermoplastic processing, PET and PEN were heated under TVA conditions at $10{ }^{\circ} \mathrm{C} \mathrm{min}{ }^{-1}$ to temperatures of 288,300 and $320{ }^{\circ} \mathrm{C}$ and held isothermally for 60 minutes. Due to the low degradation temperatures studied, the pressure changes, corresponding to the presence of both condensable and non-condensable degradation species were small i.e. less than $1 \times 10^{-3}$ Torr, in comparison to those shown previously for degradation studies up to $550{ }^{\circ} \mathrm{C}$. Online mass spectrometry did not detect any non-condensable degradation species such as carbon monoxide, methane or hydrogen from PEN. However, small traces of carbon monoxide were detected from the degradation of PET at isothermal temperatures of $300{ }^{\circ} \mathrm{C}$ and $320{ }^{\circ} \mathrm{C}$.

\subsubsection{Sub-Ambient Distillation Data for PET and PEN}

Despite minimal pressure changes, associated with the generation of volatile species from the thermal degradation of PET and PEN, four separate fractions were still collected from both polymers during the sub-ambient distillation process. The sub-ambient distillation profiles for PET and PEN following isothermal holds at $288-320{ }^{\circ} \mathrm{C}$ are illustrated in Figure 12. Significant differences were evident in the levels of condensable volatile products at the three temperatures of interest for both PET and PEN. Table 6 presents the degradation products isolated from PET and PEN at processing temperatures of $288-320{ }^{\circ} \mathrm{C}$. The composition of degradation products, identified by online MS, were found to be identical for PET and PEN at all three temperatures of interest highlighting strong similarities in the mechanisms by which both polyesters thermally degrade. IR analysis was also performed on all fractions collected from PET and PEN, and GC-MS analysis for fraction 4 species; however, due to the very small quantity of degradation products produced, identifying the exact nature of degradation products proved difficult.

On increasing the temperature from $288{ }^{\circ} \mathrm{C}$ to $320^{\circ} \mathrm{C}$, the generation of carbon dioxide was found to increase in both polyesters. Generation of carbon dioxide in PET at $320{ }^{\circ} \mathrm{C}$ was found to be significantly increased in contrast to PEN, indicative that extensive degradation, leading to the production of secondary degradation products, is increased for PET in comparison to PEN. Both PET and PEN were found to generate similar quantities of both acetaldehyde and water, identified in fractions 2 and 3, respectively. On increasing the temperature from $288{ }^{\circ} \mathrm{C}$ to $320{ }^{\circ} \mathrm{C}$, increasing quantities of acetaldehyde were generated from both PET and PEN. In addition to carbon dioxide, acetaldehyde and water, previously identified from degradation studies of PET and PEN up to temperatures of $550^{\circ} \mathrm{C}$, ethylene glycol was identified in fraction 4 from PET and PEN. 


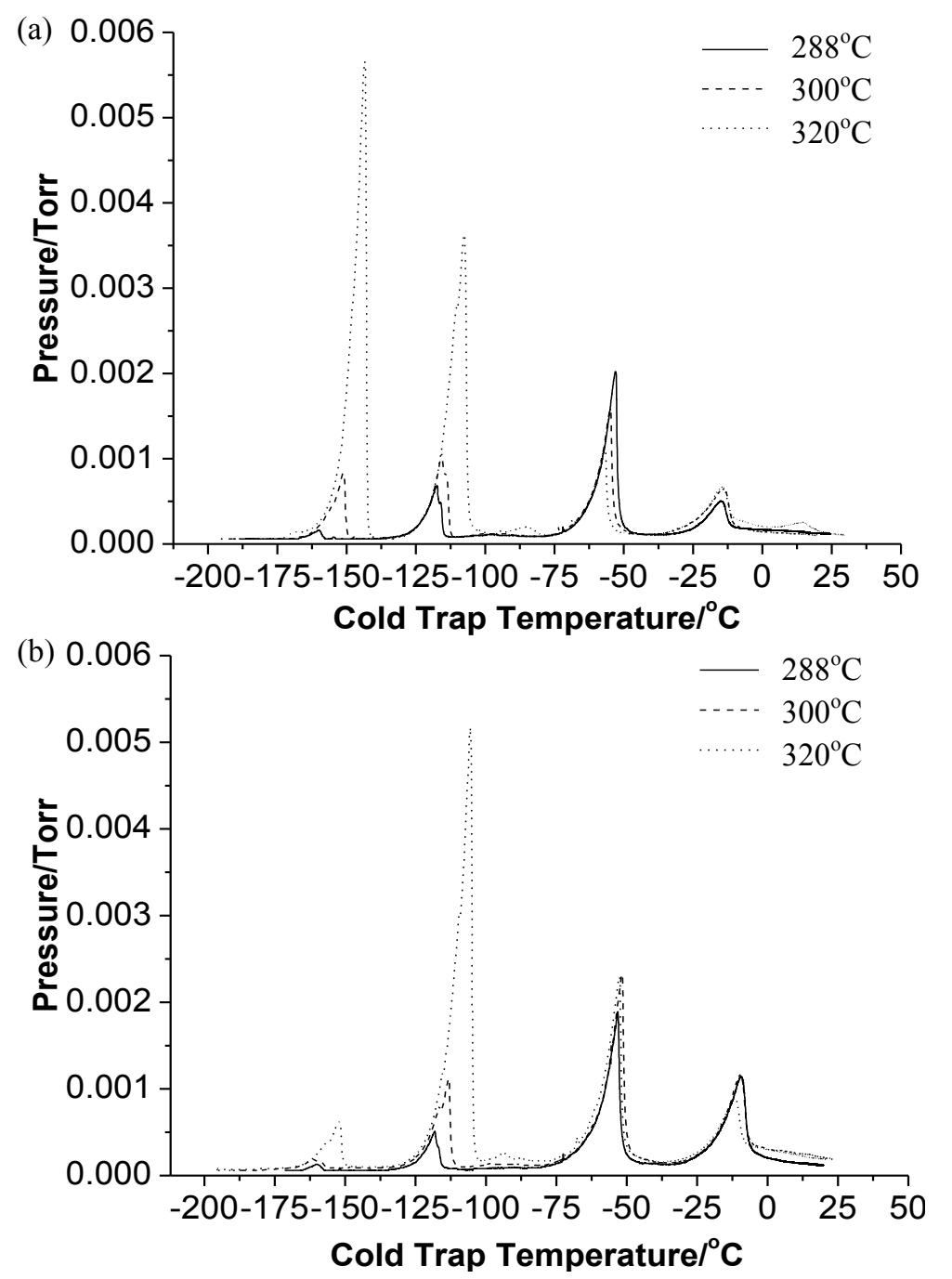

Figure 12: Sub-ambient TVA curves for degradation products of PET and PEN following isothermal holds at $288{ }^{\circ} \mathrm{C}, 300{ }^{\circ} \mathrm{C}$ and $320{ }^{\circ} \mathrm{C}$

\begin{tabular}{|c|c|c|}
\hline Fraction & Temperature range collected & Major degradation product \\
\hline 1 & $-196{ }^{\circ} \mathrm{C}$ to $-137^{\circ} \mathrm{C}$ & Carbon dioxide \\
\hline 2 & $-136^{\circ} \mathrm{C}$ to $-78^{\circ} \mathrm{C}$ & Acetaldehyde \\
\hline 3 & $-77{ }^{\circ} \mathrm{C}$ to $-40^{\circ} \mathrm{C}$ & Water \\
\hline 4 & $-39{ }^{\circ} \mathrm{C}$ to $25^{\circ} \mathrm{C}$ & Ethylene Glycol \\
\hline
\end{tabular}

Table 6: Sub-ambient distillation products collected from the degradation of both PET and PEN at temperatures of $288{ }^{\circ} \mathrm{C}, 300{ }^{\circ} \mathrm{C}$ and $320{ }^{\circ} \mathrm{C}$ 


\subsubsection{Cold Ring Fractions of PET and PEN}

The cold ring fractions from PET and PEN, containing high boiling point degradation products condensable at room temperature, were found to consist of a very small amount of white solid. Once again, due to the poor solubility of the cold ring fractions in $\mathrm{CHCl}_{3}$ and many other common laboratory solvents, the samples were primarily suited for IR analysis. The IR spectra obtained for the cold ring fractions of PET and PEN are illustrated in Figure 13.
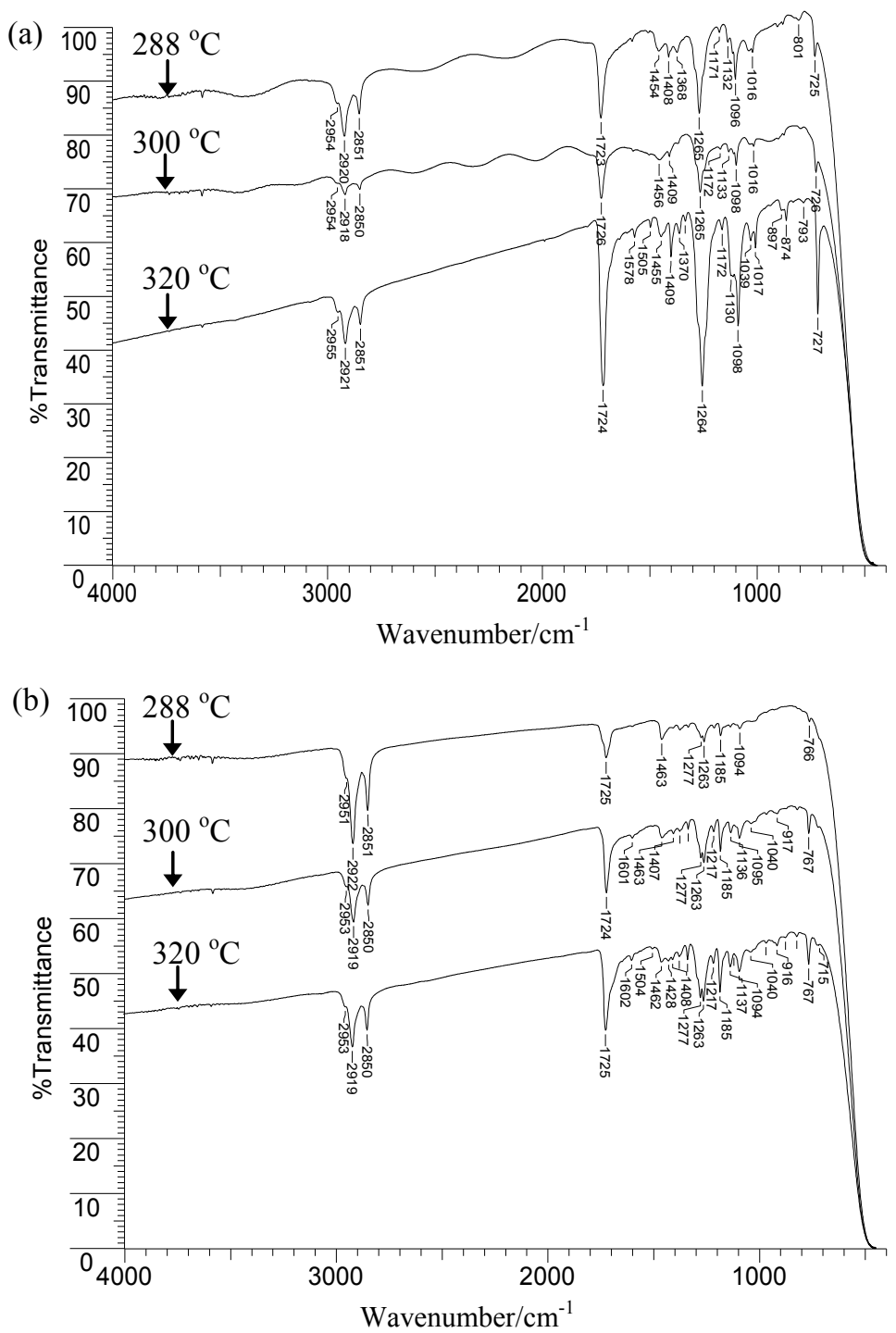

Figure 13: IR spectra of cold ring fraction from (a) PET and (b) PEN at isothermal degradation temperatures of $288{ }^{\circ} \mathrm{C}, 300{ }^{\circ} \mathrm{C}$ and $320{ }^{\circ} \mathrm{C}$

The results presented in Figure 13 indicate the presence of mainly oligomers within the cold ring fractions of PET. The IR spectra are particularly weak at the lower isothermal temperatures of $288{ }^{\circ} \mathrm{C}$ and $300{ }^{\circ} \mathrm{C}$ due to the small quantity of cold ring fraction generated; however as the concentration of 
cold ring fraction increases at $320^{\circ} \mathrm{C}$, the intensity of the IR absorption bands improves. For all PET cold ring fractions, aliphatic C-H stretching of $\mathrm{CH}_{2}$ units in PET were observed around 2954, 2920 and $2851 \mathrm{~cm}^{-1}$ alongside a $\mathrm{C}=\mathrm{O}$ absorption band at $1725 \mathrm{~cm}^{-1}$ for ester groups present in oligomeric PET. Aromatic skeletal C-H stretching from the aromatic rings in PET were evident from 1578 - 1368 $\mathrm{cm}^{-1}$ and the $\mathrm{C}(\mathrm{O})-\mathrm{O}$ stretching and bending vibrations of ester groups in PET observed at $1265 \mathrm{~cm}^{-1}$ and $1130 \mathrm{~cm}^{-1}$ respectively. Aromatic bands in the skeletal region of $1172-1016 \mathrm{~cm}^{-1}$ indicate 1,4 substitution of aromatics, in addition to IR absorption bands in the region of $874 \mathrm{~cm}^{-1}$ representing C$\mathrm{H}$ out-of-plane deformations of para-substituted benzene rings in PET. The aromatic $\mathrm{C}-\mathrm{H}$ bending mode from disubstituted benzene rings in PET can be observed at $727 \mathrm{~cm}^{-1}$. A lack of carboxylic acid or vinyl ester absorption bands must be highlighted from this IR analysis indicative that the oligomers of PET generated at typical processing temperatures are most likely to be cyclic rather than linear oligomers as observed for degradation up to $550{ }^{\circ} \mathrm{C}$.

Similarly, the cold ring fractions collected from the isothermal degradation studies of PEN were also found to contain short chain oligomers of PEN. As illustrated in Figure 13, the IR absorption bands are weak due to the small quantity of cold ring fraction obtained from each analysis. Aliphatic $\mathrm{C}-\mathrm{H}$ stretching of the $\mathrm{CH}_{2}$ units in PEN can be observed at 2920 and $2850 \mathrm{~cm}^{-1}$ alongside a $\mathrm{C}=\mathrm{O}$ absorption band at $1725 \mathrm{~cm}^{-1}$ for ester groups present in oligomeric PEN. Aromatic skeletal C-H stretching from the aromatic rings in PEN are evident from 1601 to $1408 \mathrm{~cm}^{-1}$ and the $\mathrm{C}(\mathrm{O})-\mathrm{O}$ stretching vibrations of ester groups can be observed at 1277, 1263 and $1185 \mathrm{~cm}^{-1}$. C(O)-O bending vibrations of ester groups in PEN are also evident at 1137 and $1095 \mathrm{~cm}^{-1}$ with out of plane deformations of two carbonyl substituents on aromatic rings visible around $767 \mathrm{~cm}^{-1}$. These IR bands, observed at all three isothermal temperatures, are all identical to those observed in the cold ring fractions of PEN when degraded up to $550{ }^{\circ} \mathrm{C}$. Again, as for PET, key IR absorption bands are absent for carboxylic acid and vinyl end groups indicating that the cold ring fraction of PEN is most likely to consist of cyclic oligomers rather than linear oligomers.

\subsection{Discussion of the Thermal Degradation Mechanisms in PET and PEN at Processing Temperatures}

From the thermal degradation studies of PET and PEN at typical processing temperatures, it is evident that few degradation species reach the main cold trap, in comparison to the significant quantity of degradation species reported from TVA studies at temperatures of $550{ }^{\circ} \mathrm{C}$. This highlights a significant reduction in the extent of thermal degradation in both PET and PEN. 
The formation of significant quantities of carbon monoxide and carbon dioxide, formed from secondary chain scission reactions of the polymer chains, was found to be absent during the degradation of PEN at temperatures of $288-320^{\circ} \mathrm{C}$. Traces of carbon monoxide and carbon dioxide were detected from the degradation of PET at $300{ }^{\circ} \mathrm{C}$ and $320{ }^{\circ} \mathrm{C}$. This is not entirely surprising due to the reduced thermal stability of PET in comparison to PEN. The formation of carbon monoxide and carbon dioxide from the degradation of PET indicates that the overall extent of thermal degradation occurring in PET is increased in comparison to PEN.

Despite the limited evolution of condensable volatile degradation species in the main cold trap during the isothermal degradation studies of PET and PEN, oligomers were identified in the cold ring fractions of both PET and PEN at all three temperatures. Due to the absence of carboxylic acid or vinyl end groups in the IR spectra for the cold ring fractions of PET and PEN, it is thought that these oligomers are cyclic and not linear oligomers. These observations are in agreement with the degradation mechanism proposed by Montaudo et al. ${ }^{[13]}$ who studied the degradation products of PET at processing temperatures $\left(270-370{ }^{\circ} \mathrm{C}\right)$ using MALDI spectrometry. Montaudo et al. report that the main degradation products observed from PET are cyclic oligomers which only open and degrade after prolonged exposure to heat and increased temperatures (i.e. greater than $370{ }^{\circ} \mathrm{C}$ ). Therefore, it is thought that the formation of cyclic oligomers is the dominant degradation reaction in PET and PEN at temperatures of $288-320^{\circ} \mathrm{C}$. These cyclic oligomers are believed to then undergo a series of further degradation reactions to produce species such as acetaldehyde and ethylene glycol, with more extensive degradation occurring in PET than PEN. The formation of these degradation products is thought to occur via ionic processes, and not radical chain scission reactions due to the absence of significant quantities of carbon monoxide and carbon dioxide. An ionic mechanism for the formation of cyclic oligomers in PEN is proposed in Scheme 5. This reaction mechanism proposed is thought to be identical for the formation of cyclic oligomers in PET. However, the extent of cyclic oligomer formation is expected to be reduced in PEN, in comparison to PET, due to the presence of bulky naphthalene species reducing the ease at which such back-biting mechanisms can occur.

The intramolecular cyclisation reaction illustrated in Scheme 5, results in the formation of cyclic oligomers and hydroxyl-chain end groups. These hydroxyl-chain end groups can then undergo scission to result in the formation of vinyl alcohol, which can rearrange instantaneously to form acetaldehyde. This reaction is illustrated in Scheme 6. Additionally, it is proposed that the hydroxylchain end groups undergo another intramolecular cyclisation reaction with oligomeric PEN to result in the formation of ethylene glycol. This reaction is illustrated in Scheme 7. Both ionic reaction Schemes 6 and 7 are thought to be identical for PET and PEN. 


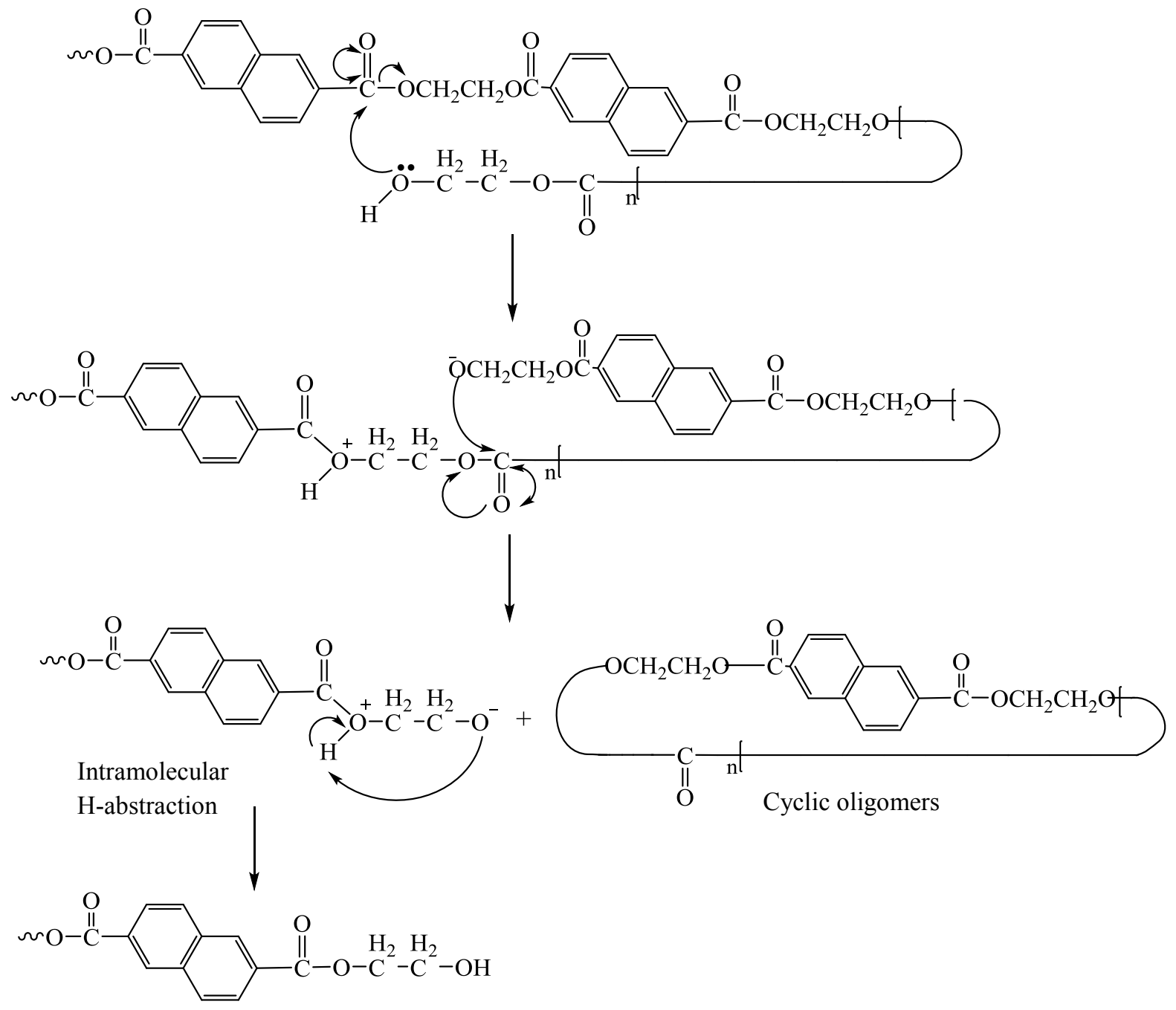

Hydroxyl chain end group

Scheme 5: Mechanism for the formation of cyclic oligomers in PEN 


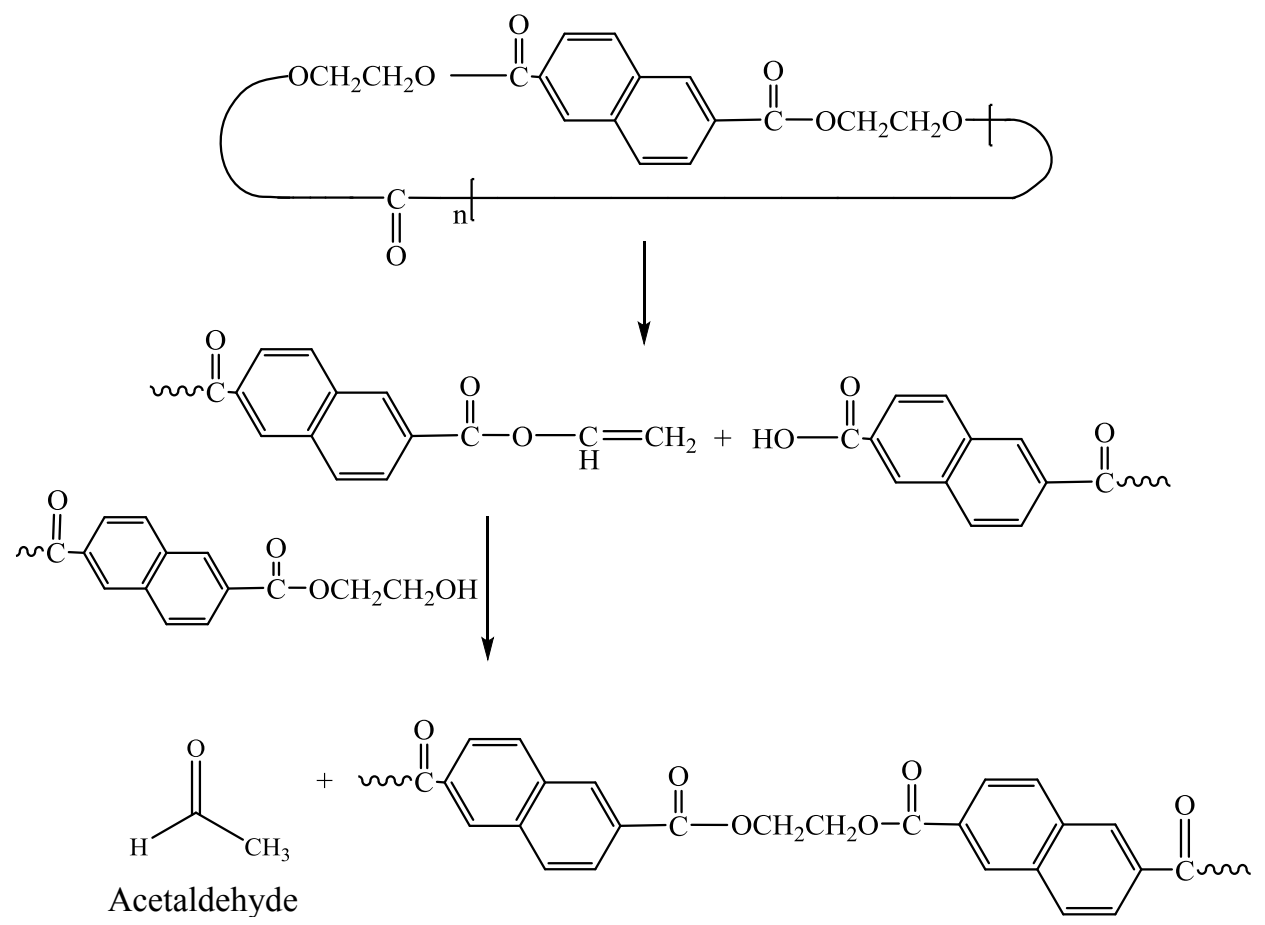

Scheme 6: Mechanism for the formation of acetaldehyde in PEN from cyclic oligomers

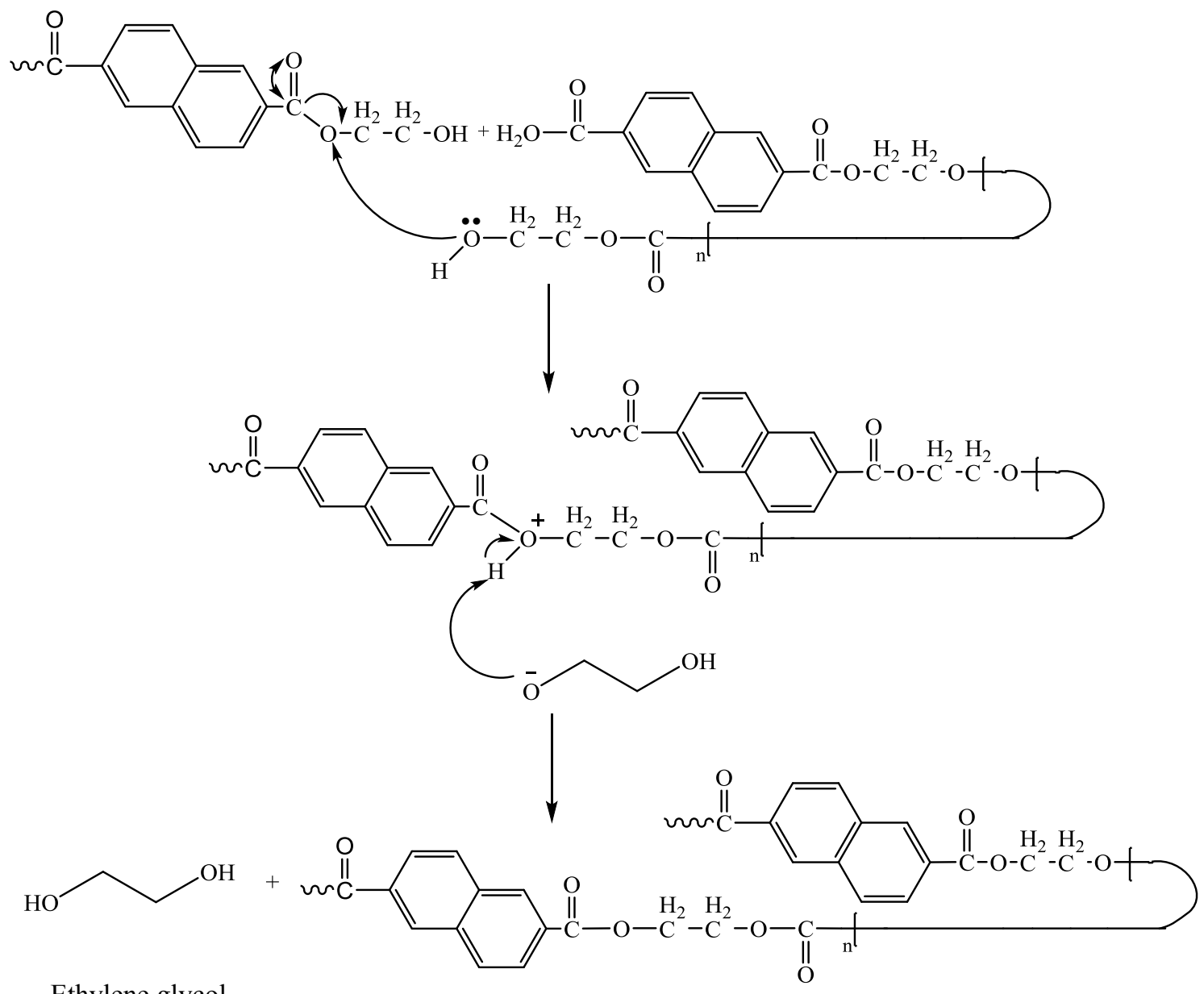

Ethylene glycol

Scheme 7: Mechanism for the formation of ethylene glycol in PEN 


\section{CONCLUSIONS}

The thermal analysis data presented in this paper highlights strong similarities in the degradation behaviour of PET and PEN. It has been demonstrated that PET and PEN only undergo one major thermal degradation process. This primary thermal degradation reaction is thought to be identical for both polyesters and involves scission of the ester bonds in the polyester backbone resulting in the formation of vinyl ester and carboxylic acid end groups.

Evolved gas analysis studies on the thermal degradation of PEN up to temperatures of $550{ }^{\circ} \mathrm{C}$ reveal that degradation is likely to proceed via a radical based degradation mechanism. The action of homolytic bond scissions, occurring in the PEN backbone throughout the temperature region of $400-550{ }^{\circ} \mathrm{C}$, not only accounts for the significant quantities of carbon monoxide and carbon dioxide observed, but the variety of additional degradation products detected. Despite an observed increase in the overall thermal stability of PEN over its terephthalate counterpart, a mechanism for the thermal degradation of PEN has been proposed to account for the generation of all degradation species that correlates well with the TVA degradation mechanisms presented in the literature for PET. ${ }^{[1]}$

In contrast with high temperature thermal degradation studies of PET and PEN, it has been reported that ionic degradation reactions are dominant in both polyesters at processing temperatures due to the absence of significant quantities of carbon monoxide and carbon dioxide. Despite limited evolution of non-condensable and condensable volatile degradation species during degradation studies of PET and PEN at typical processing temperatures, the formation of cyclic oligomers has been proposed as the dominant degradation reaction. An identical reaction mechanism has been suggested for the formation of cyclic oligomers in PET and PEN; however the extent of cyclic oligomer formation is believed to be reduced in PEN, in comparison to PET, due to the presence of bulky naphthalene species reducing the ease at which such back-biting mechanisms can occur. Following formation of these cyclic oligomers via intramolecular cyclisation reactions, a series of further degradation reactions occur after prolonged exposure to generate acetaldehyde and ethylene glycol, with more extensive cyclic oligomer degradation thought to occur in PET than PEN due to the reduced thermal stability of PET in contrast to PEN.

A combination of both ionic and homolytic thermal degradation reactions have therefore been proposed to occur over the temperature range of degradation i.e. $288-550{ }^{\circ} \mathrm{C}$. The data presented in this paper, suggests that an ionic based mechanism dominates at lower temperatures in PET and PEN due to the absence of carbon oxides. On increasing the temperature, radical based degradation processes have been suggested as the dominant reaction in both polyesters due to significant generation of carbon monoxide and carbon dioxide. 


\section{REFERENCES}

1. Whinfield JR, Dickson JT. British. Patent, 1941, 578079.

2. Whinfield JR. Chemistry of Terylene, Nature, 1946;158:930-941.

3. Plastics Europe Market Research Group; Facts and Figures; The Compelling Facts about Plastics - An analysis of European plastics production, demand and recovery for 2011; http://www.plasticseurope.org; Viewed November 2012.

4. Mackintosh AR, Liggat JJ. Dynamic mechanical analysis of poly(trimethylene terephthalate) - A comparison with poly(ethylene terephthalate) and poly(ethylene naphthalate J App Polym Sci 2004;92:2791-2796.

5. McGonigle EA, Liggat JJ, Pethrick RA, Jenkins SD, Daly JH, Hayward D. Permeability of $\mathrm{N}_{2}, \mathrm{Ar}, \mathrm{He}, \mathrm{O}_{2}$, and $\mathrm{CO}_{2}$ through as extruded amorphous and biaxially oriented polyester films: Dependence on chain mobility Polymer, 2001;42:2413-2426.

6. Seirs J, Long, TE. Modern Polyesters: Chemistry and Technology of Polyesters and Copolyesters, J Wiley and Sons Ltd, UK, 2003.

7. Brooks DW, Giles GA. PET Packaging Technology, Taylor and Francis, UK, 2002.

8. Turnbull L, Liggat JJ, MacDonald WA. Ageing of poly(ethylene terephthalate) and poly(ethylene naphthalate) under moderately accelerated conditions, J App Polym Sci 2012;124:4517 - 4529 .

9. Botelho G, Quieros A, Gijsman PJ. Studies on thermal and thermo-oxidative degradation of poly(ethylene terephthalate) and poly(butylene terephthalate) Polym Degrad Stab 2000;70:299-304.

10. Buxbaum LH. Degradation of poly(ethylene terephthalate) Agnew Chem Int Ed 1968, 7, 182-186.

11. McNeill IC, Bounekhel M. Thermal-degradation studies of terephthalate polyesters 1. Poly(alkylene terephthalates) Polym Degrad Stab 1991;34:187-204

12. Zimmermann H, Kim NT. Investigations on thermal and hydrolytic degradation of poly(ethylene terephthalate) Polym Eng Sci 1980;20:680-683.

13. Montaudo G, Puglisi C, Samperi F. Primary thermal-degradation mechanisms of PET and PBT Polym Degrad Stab 1993;42:13-28

14. McNeill IC. Thermal volatilisation analysis, a new method for the characterisation of polymers and the study of polymer degradation. J Polym Sci A1, 1966;4:2479.

15. McNeill IC, Thermal volatilisation analysis of high polymers Eur Polym J, 1967; 3:409. 
16. McNeill IC, Polymer degradation and characterisation by thermal volatilization analysis with differential condensation of products, Eur Polym J, 1970;6:373-395.

17. McNeill IC, Ackerman L, Gupta SN, Zulfiqar M, Zulfiqar S. Analysis of degradation products by thermal volatilization analysis at subambient temperatures, J Polym Sci, Polym Chem Ed, 1977; 15:2381-2392.

18. Holland BJ, Hay JN. Polymer, 2002;43:1835-1847.

19. Yang J, Xia Z, Kong F, Ma X. Polym Degrad Stab 2010;95:53-58.

20. Holland BJ, Hay JN, Polymer, 2002;43:1797-1804. 